\title{
REVIEW \\ Vitamin D and spinal cord injury: should we care?
}

\author{
J Lamarche $^{1}$ and G Mailhot ${ }^{2,3}$
}

Study design: Narrative review.

Objectives: This review provides an overview of the etiological factors and consequences of vitamin $\mathrm{D}$ insufficiency in relation to spinal cord injury (SCI) as well as important considerations for vitamin D supplementation.

Setting: Montreal, Canada.

Methods: Literature search.

Results: Vitamin D insufficiency is common in SCl individuals owing to the presence of many contributing factors including limited sun exposure and intake, use of medication and endocrine perturbations. Although there are several biological plausible mechanisms by which vitamin D may act upon musculoskeletal and cardiometabolic health, the impact of vitamin D insufficiency on such systems remains ill defined in SCl. In the absence of guidelines for the management of vitamin D insufficiency in this high-risk population and in an attempt to provide clinical guidance, considerations for vitamin D supplementation such as the type of vitamin D, dosing regimens and toxicity are discussed and tentative recommendations suggested with particular reference to issues faced by SCl patients.

Conclusion: Although high rates of vitamin D insufficiency are encountered in SCl individuals, its consequences and the amount of vitamin D required to prevent insufficiency are still unknown, indicating a need for more intervention studies with well-defined outcome measures. Routine screening and monitoring of vitamin D as well as treatment of suboptimal status should be instituted in both acute and chronic setting. The close interactions between vitamin D and related bone minerals should be kept in mind when supplementing $\mathrm{SCl}$ individuals, and practices should be individualized with clinical conditions.

Spinal Cord (2016) 54, 1060-1075; doi:10.1038/sc.2016.131; published online 20 September 2016

\section{INTRODUCTION}

Well known for its regulation of calcium and phosphate homeostasis as well as its skeletal effects, vitamin D has gained increasing attention in recent years for its actions that go beyond bone health. Indeed, observational studies demonstrating positive associations between 25-hydroxyvitamin D (25OHD) levels (the major circulating vitamin D metabolite) and several clinical outcomes, including immune responses, lung and muscle function, cardiovascular health and chronic diseases such as obesity and diabetes, have received much recognition. ${ }^{1}$

Practitioners working with spinal cord-injured individuals are confronted with early-onset osteoporosis and a rate of fractures exceeding those found in postmenopausal women. ${ }^{2}$ Furthermore, individuals with spinal cord injury (SCI) experience neuroinflammation, impaired lung function, muscle dysfunction and accelerated cardiometabolic disease, all of which may benefit from the optimization of vitamin D nutrition. However, despite our increasing knowledge of the extra-skeletal roles of vitamin $\mathrm{D}$, this vitamin has been scarcely studied in SCI in relation to other outcomes.

The purpose of this narrative review is to provide an overview of vitamin D in relation to SCI with a special focus on the musculoskeletal system and cardiometabolic health as well as on critical considerations for vitamin D supplementation. A better knowledge of the importance of this vitamin for SCI individuals may lead to improvements in nutritional management, inform the development of clinical practice guidelines and emphasize the need for more research in this area.

\section{VITAMIN D METABOLISM}

Vitamin $\mathrm{D}$ is a generic term that comprises the animal-derived cholecalciferol (vitamin $\mathrm{D}_{3}$ ) and the plant-derived ergocalciferol (vitamin $\mathrm{D}_{2}$ ). Both forms can be found in foods and supplements, whereas only cholecalciferol can be synthesized in the skin upon exposure to ultraviolet-B (UVB) radiation. Fatty fish, including salmon, mackerel and sardines, and fish oils exhibit the highest natural amount of vitamin $D_{3}$. Other significant sources of vitamin $D_{3}$ comprise fortified milk, some brands of yogurt made with fortified milk, egg yolks and liver. Vitamin $\mathrm{D}_{2}$ is produced in UVB-irradiated fungi and yeast, although its occurrence in foods is even more limited than vitamin $\mathrm{D}_{3}$. Commercially irradiated mushrooms and breads made with irradiated yeast provide only small amounts of vitamin $\mathrm{D}_{2}$. Plant-based non-dairy beverages (for example, soy, rice and almonds) are usually fortified with either vitamin $\mathrm{D}_{2}$ or vitamin $\mathrm{D}_{3}{ }^{3-5}$

Vitamin D from cutaneous synthesis or dietary/supplemental intake is transported in the circulation and binds to the D-binding protein (DBP). It can be taken up by the adipose tissue for storage, although very limited data exist on the exact amount of vitamin D stored in fat and on the rate of exchange between adipose tissue and the

${ }^{1}$ Center for Interdisciplinary Research in Rehabilitation, CIUSS Centre-Sud-Montreal Gingras-Lindsay Rehabilitation Center, Montreal, QC, Canada; ${ }^{2}$ Research Centre, CHU Sainte-Justine, Montreal, QC, Canada and ${ }^{3}$ Department of Nutrition, Université de Montréal, Montréal, QC, Canada

Correspondence: J Lamarche, Center for Interdisciplinary Research in Rehabilitation, CIUSSS Centre-Sud, Montreal Gingras-Lindsay Rehabilitation Center, 6300 Darlington Avenue, Montreal, QC, Canada H3S2J4.

E-mail: josee.lamarche.irglm@ssss.gouv.qc.ca

Received 16 February 2016; revised 26 July 2016; accepted 11 August 2016; published online 20 September 2016 
bloodstream. Vitamin D is considered a prohormone as it undergoes two successive hydroxylation steps before gaining biological activity. The first step occurs in the liver and consists of the hydroxylation at the carbon 25-position to yield the intermediate 25OHD. 25OHD is considered a measure of total exposure (sun, food and supplements) and constitutes the metabolite universally accepted to clinically assess vitamin D status. The second hydroxylation, which takes place in the kidneys and in extra-renal tissues, involves the carbon 1 of $25 \mathrm{OHD}$ and generates the bioactive form 1,25-dihydroxyvitamin D $\left(1,25(\mathrm{OH})_{2} \mathrm{D}\right)$, which interacts with its ubiquitous nuclear receptor (vitamin D receptor; VDR) to modulate the transcription of a wide set of genes. Depending on its site of synthesis, $1,25(\mathrm{OH})_{2} \mathrm{D}$ exerts endocrine and auto- or paracrine effects. Endocrine actions of vitamin $\mathrm{D}$ are attributed to the renal $1,25(\mathrm{OH})_{2} \mathrm{D}$ and are classically involved in calcium and phosphate homeostasis whereby $1,25(\mathrm{OH})_{2} \mathrm{D}$ stimulates both intestinal absorption of calcium and phosphate. In contrast, the auto/paracrine vitamin D system relies on the extra-renal production of $1,25(\mathrm{OH})_{2} \mathrm{D}^{6}{ }^{6} 1-\alpha$ hydroxylase (CYP27B1), the enzyme that converts the major circulating compound $25 \mathrm{OHD}$ to $1,25(\mathrm{OH})_{2} \mathrm{D}$, is expressed in a number of cells and tissues including, among others, monocytes, keratinocytes, osteoblasts, enterocytes, prostate and mammary tissue. Thus, the extra-skeletal effects of vitamin $\mathrm{D}$ are strongly dependent on the level of circulating 25OHD.

As opposed to $25 \mathrm{OHD}$ and despite being the biologically active form, $1,25(\mathrm{OH})_{2} \mathrm{D}$ exhibits a very short half-life (that is, $4-15 \mathrm{~h}$ ) and is thus not considered a good marker of vitamin D status. Furthermore, despite circulating $25 \mathrm{OHD}$ indicative of insufficiency, $1,25(\mathrm{OH})_{2} \mathrm{D}$ levels may remain normal or even elevated as a result of the fall in serum ionized calcium that triggers a rise in serum parathyroid hormone $(\mathrm{PTH})$, which in turn increases the renal 1- $\alpha$ hydroxylase activity.

\section{VITAMIN D STATUS OF SCI INDIVIDUALS}

The first report on impaired vitamin D status in SCI individuals occurred in the early 1990 s. $^{7}$ Since then, studies, exclusively cross-sectional in nature, have documented varying degrees of vitamin D insufficiency in individuals with SCI using different cutoffs of insufficiency. Although studies included individuals with paraplegia and tetraplegia as well as traumatic and non-traumatic individuals, the distribution of AIS impairment scales among participants was rarely mentioned. In addition, most of the participants were in the chronic rather than the acute phase and the length of time post injury varied considerably among studies. Furthermore, middle-aged and older men were studied more than younger people and women. Very few studies included anthropometric measurements, and only one has evaluated dietary intakes of vitamin $\mathrm{D}$, calcium and phosphorus. ${ }^{8}$

Using a cutoff level of $25 \mathrm{OHD}$ of $40 \mathrm{nmoll}^{-1}$, Bauman et al. ${ }^{9}$ observed that $32 \%$ of veterans with chronic SCI exhibited vitamin D deficiency. Javidan et al. ${ }^{8}$ found that $53 \%$ of Iranian individuals with chronic SCI were vitamin D deficient, which is defined as a 25OHD level below $32.5 \mathrm{nmoll}^{-1}$. More recently, using a higher threshold for insufficiency $\left(75-80 \mathrm{nmol}^{-1}\right)$, several authors reported prevalence ranging from 39 to $93 \%$ in either acute or chronic SCI individuals. ${ }^{10-13}$ Black ethnicity, winter season, younger age, chronicity, degree of incompleteness and paraplegia were all found to be associated with $25 \mathrm{OHD}$ levels. ${ }^{10}$ As these studies are of crosssectional design, they do not allow distinguishing between newly occurring, recent or long-standing suboptimal vitamin $\mathrm{D}$ status. Results of studies comparing 25OHD levels of chronic SCI individuals with that of a control group made up of able-bodied individuals were inconsistent, with some showing no difference between groups ${ }^{13,14}$ and others reporting reduced 25OHD levels in individuals with chronic SCI. ${ }^{9}$ Although mean $25 \mathrm{OHD}$ levels did not always differ from those of controls, SCI individuals continually exhibited a higher prevalence of vitamin D deficiency or insufficiency. ${ }^{13}$

Intervention studies on vitamin D and SCI are scarce and were all conducted by the same group. ${ }^{15-17}$ These studies were characterized by small sample size (ithat is, 7-40) as well as considerable differences in age range (that is, 25-68 years old), study duration (that is, 14 days to 12 months) and length post injury (that is, 1-48 years). Supplemental vitamin $\mathrm{D}_{3}$ varied from 800 to 2000 IU daily in combination with the equivalent of calcium carbonate ranging from 800 to $3250 \mathrm{mg}$ daily, and supplements were given as fixed dose irrespective of baseline vitamin D status.

Daily administration of 800 IU failed to completely reverse vitamin D insufficiency, defined in this study as serum 25OHD levels less than $40 \mathrm{nmoll}^{-1}$. Before the initiation of supplementation, $82 \%$ of subjects had insufficient 25OHD levels, whereas 15-20\% of individuals still exhibited vitamin D insufficiency after 12 months of supplementation. ${ }^{15}$ On the other hand, a 3-month regimen of 2000 IU per day of $\mathrm{D}_{3}$ resulted in $25 \mathrm{OHD}$ levels above $75 \mathrm{nmol}^{-1}$ in all subjects but one. ${ }^{16}$ In the absence of more evidence, these studies suggest at least that $2000 \mathrm{IU}$ is better than $800 \mathrm{IU}$ of $\mathrm{D}_{3}$ in achieving a state of vitamin D sufficiency in SCI individuals.

\section{ETIOLOGY OF SUBOPTIMAL VITAMIN D STATUS}

\section{Insufficient sun exposure and limited intake}

The most inexpensive way of getting vitamin $\mathrm{D}$ remains short casual, yet unprotected, sun exposure. Upon exposure to UVB radiation, the precursor 7-dehydrocholesterol, present in the cell membrane of both skin keratinocytes and fibroblasts, is converted to previtamin $\mathrm{D}_{3}$, which is subsequently metabolized to vitamin $\mathrm{D}_{3}$. Vitamin $\mathrm{D}_{3}$ is then carried to the bloodstream and is bound to DBP. Because of thermoregulatory disorders, high sensitivity to heat and/or protection against sunburn, SCI individuals are instructed to avoid or reduce sun exposure, which greatly limits their capacity of getting vitamin D through this source. Of note, sunscreen with a sun protection factor greater than eight significantly reduces the capacity of skin to synthesize vitamin D. ${ }^{18}$ In addition, SCI individuals are more likely to be institutionalized or homebound, which may reduce sun exposure. However, Smith et al. ${ }^{19}$ have failed to find a relationship between 25OHD levels and mobility status in a group composed of individuals of varying disabilities. To date, no data exist on the level of sun exposure in SCI individuals. The lack of standardized and validated questionnaires clearly constitutes an obstacle to adequately address the level of sun exposure and its relationship with vitamin D levels.

Oral intake thus represents the other alternative to get enough vitamin D. In a Canadian study, vitamin D intake of chronic SCI individuals fell below the recommendations, with mean intakes of 120 and $61 \mathrm{IU}$ in men and women, respectively. ${ }^{20}$ At baseline, $22 \%$ of participants reported taking a supplement of vitamin D. Intake of vitamin $\mathrm{D}$ through dairy products is also low among individuals with SCI. Tomey et al. ${ }^{21}$ reported in community-dwelling men with paraplegia that only $16 \%$ of them met the guidelines for dairy servings. Oleson et al. ${ }^{10}$ have reported that many individuals with SCI deliberately restrict or receive unsuitable advice to eliminate milk consumption and other products rich in calcium and vitamin $\mathrm{D}$ in order to minimize the risk of developing kidney stones. Low calcium intake, especially when coupled with suboptimal vitamin D status, exerts a strong impact on bone metabolism. If 25OHD levels are low, one would expect intestinal calcium absorption to be reduced, 
a state that might be further depressed if calcium intake is inadequate. Impairment in calcium absorption results in secondary hyperparathyroidism, which enhances bone turnover through its stimulating effect on the bone-resorbing cell osteoclasts. Thus, vitamin $\mathrm{D}$ as well as calcium intakes should be closely monitored in SCI individuals.

Finally, although nutrient absorption has been reported as normal in individuals with SCI, it should be kept in mind that these individuals may experience intestinal motility disorders that might impair vitamin $\mathrm{D}$ absorption. However, to date, no study has specifically investigated this aspect in this population of individuals.

\section{Use of medication}

The use of certain medications, especially those metabolized by the P450 cytochrome CYP3A4, may lead to decreased 25OHD levels. ${ }^{22}$ Besides being a major hepatic and intestinal drug-metabolizing enzyme, CYP3A4 is also involved in metabolic clearance of $25 \mathrm{OHD}$, particularly under conditions of induced CYP3A4 expression. Some CYP3A4-inducing drugs may therefore interfere with vitamin D metabolism, resulting in reduced levels of serum 25OHD. Given that SCI individuals may use many CYP3A4-inducing drugs that have been linked to reduced levels of $25 \mathrm{OHD}$, such as the anticonvulsants carbamazepine and phenytoin, and the antibiotic rifampin, the use of such medications should be considered a potential contributing factor to vitamin D insufficiency in SCI. ${ }^{23-30}$ Thus far, the association between anticonvulsant use and vitamin $\mathrm{D}$ status has been explored in SCI individuals in only one study, and the authors have reported no difference in 25OHD levels between users and non-users of anticonvulsants. ${ }^{13}$ However, the low number of users vs non-users precludes any firm conclusion.

\section{Alcohol use \\ Alcohol abuse at the time of injury and post injury has been reported as common in SCI individuals. ${ }^{31,32}$ Low levels of 25OHD have been reported in chronic alcoholics, ${ }^{33}$ but seem to be related to poor nutrition and reduced sun exposure rather than impairment in liver activity, a key organ for vitamin D metabolism. ${ }^{34}$ Nevertheless, SCI individuals with heavy alcohol use should deserve special attention with respect to their vitamin D status.}

\section{Kidney disease}

The kidney is a central organ for vitamin D metabolism as it is the principal site for the conversion of $25 \mathrm{OHD}$ to the active form 1,25 $(\mathrm{OH})_{2} \mathrm{D}$. Chronic kidney disease $(\mathrm{CKD})$ is characterized by the progressive loss of renal capacity to synthesize $1,25(\mathrm{OH})_{2} \mathrm{D}$, which results in secondary hyperparathyroidism, skeletal abnormalities and excessive serum calcium and phosphate predisposing to ectopic calcification. ${ }^{35}$ Furthermore, an $80 \%$ incidence of vitamin D insufficiency (25OHD levels $<50 \mathrm{nmol}^{-1}$ ) has been reported in CKD individuals. ${ }^{36}$ This observation is intriguing as it is in the liver, rather than in the kidney, that the synthesis of 25OHD takes place. More importantly, vitamin D insufficiency represents a risk factor higher than $1,25(\mathrm{OH})_{2} \mathrm{D}$ deficiency for the progression of renal damage to end-stage renal disease and death. ${ }^{37}$

SCI individuals are more likely to develop CKD because they exhibit additional risk factors including a higher prevalence of chronic urinary infections, neurogenic bladder dysfunction and nephrolithiasis. CKD prevalence was found to be $35.2 \%$ in a large cohort of American veterans with SCI. ${ }^{38}$ Given this high prevalence, its impact on a wide range of biological functions including the synthesis of the bioactive form of vitamin D and the consequences of vitamin D insufficiency on the prognosis of renal disease, more attention should be paid to the vitamin D status of SCI individuals, especially those with CKD.

\section{Obesity}

Obese individuals display reduced concentrations of 25OHD and a high prevalence of vitamin $\mathrm{D}$ insufficiency. The reasons why obese individuals are prone to vitamin D insufficiency are still unclear. It has been hypothesized that obese people exhibit an enhanced clearance of vitamin $\mathrm{D}$ secondary to the increased uptake and storage in the fat compartments. ${ }^{39}$ Using a dose-response design, Gallagher et al. ${ }^{40}$ compared the response of thin, overweight and obese postmenopausal women to increasing doses of vitamin $\mathrm{D}_{3}$. Serum 25OHD levels at baseline and after 12 months of supplementation were found to be lower in the overweight and obese women. However, the dose-response curves were parallel between the BMI categories, suggesting that the difference in serum $25 \mathrm{OHD}$ levels may have been due to a volume dilution effect rather than the trapping of vitamin $\mathrm{D}$ in excess body fat.

It has been reported that obesity is more prevalent among individuals with disabilities than in the general population. ${ }^{41}$ Prevalence rates of overweight and obesity range from 40 to $66 \%$ in SCI individuals, but remain similar to those of the able-bodied population..$^{21,42,43}$ However, individuals with SCI have a greater percentage of body fat than does the able-bodied population. ${ }^{44}$ Whether this gain of adipose tissue contributes to alter vitamin D pharmacokinetics and body distribution, which, in turn, may potentially influence the vitamin D status, is unknown.

\section{Endocrine perturbations related to SCI}

SCI individuals also experience perturbations of the calciumphosphate-parathormone axis that take place soon after the injury and may impact the vitamin D system. These perturbations originate from the increased bone resorption that occurs shortly after the injury as a result of the immobilization and neurological impairment.

In acute SCI, PTH suppression is correlated with neurological impairment ${ }^{45}$ with greater suppression being observed in individuals with AIS A impairment. PTH levels drop abruptly as a result of the high bone resorption that increases calcium release in the bloodstream. ${ }^{15,46,47}$ Small variations in serum calcium are detected by the calcium-sensing receptor located on the parathyroid glands. Decrease in serum calcium leads to the stimulation of this receptor and the release of $\mathrm{PTH}$, whereas elevated blood calcium levels exert the opposite effect and inhibit its secretion. Given that $\mathrm{PTH}$ stimulates the renal conversion of $25 \mathrm{OHD}$ to its bioactive form, $1,25(\mathrm{OH})_{2} \mathrm{D}$ levels are reduced when serum calcium levels are elevated. $^{45,48}$ However, hypoparathyroidism appears transient as PTH levels were found to return to normal after 6 months of follow-up. ${ }^{46}$ Excessive bone resorption also induces an efflux of phosphorus from bone tissue. Increased serum phosphorus exerts a negative impact on the activity of the 1- $\alpha$ hydroxylase, further decreasing the production of $1,25(\mathrm{OH})_{2} \mathrm{D}$.

In contrast, circulating PTH and $1,25(\mathrm{OH})_{2} \mathrm{D}$ tend to increase during the chronic SCI phase. (13), ${ }^{49}$ However, some authors have also reported sustained PTH suppression in individuals with longstanding SCI. ${ }^{14}$

\section{CONSEQUENCES OF IMPAIRED VITAMIN D STATUS FOR SCI INDIVIDUALS}

\section{Musculoskeletal health}

Bone. Whether vitamin $\mathrm{D}$ acts directly on the bone or indirectly, through the stimulation of calcium and phosphate intestinal 
absorption, which results in their adequate provision to bone, remains an unresolved issue. Although studies conducted with $V d r$ and/or Cyp27b1 knockout mice have provided insights showing that the major effect of vitamin D lies in its ability to regulate calcium and phosphate homeostasis, in vitro studies have supported a direct bone effect of the metabolite $1,25(\mathrm{OH})_{2} \mathrm{D}$. $1,25(\mathrm{OH})_{2} \mathrm{D}$, through its interaction with the VDR, can stimulate the differentiation of osteoblasts and osteoclasts. Moreover, the osteoblast possesses the enzymatic machinery to produce the bioactive form of vitamin $\mathrm{D}$ locally from the circulating $25 \mathrm{OHD}$, which in turn modulates osteoblast differentiation and secretion of various proteins including type I collagen, osteocalcin and the osteoclast differentiation factor, RANKL. Low serum 25OHD may therefore have an impact on these cells by reducing the amount of endogenously produced $1,25(\mathrm{OH})_{2} \mathrm{D}$. Priemel et al. ${ }^{50}$ performed a postmortem histomorphometric analysis of 675 iliac crest biopsies from German adults who had no evidence of bone disease. They found that $20 \%$ of the studied population exhibited some mineralization defects. Surprisingly, they failed to find such defects in individuals with $25 \mathrm{OHD}$ levels above $75 \mathrm{nmoll}^{-1}$. Furthermore, Busse et al. ${ }^{51}$ have reported impaired bone quality in vitamin D-deficient otherwise healthy subjects. In this study, they showed, quite elegantly, that vitamin D deficiency is associated with aging of bone tissue and compromised structural integrity.

Osteoporosis is a condition, characterized by bone microarchitectural disruption, that increases bone fragility and the propensity for fracture. Bone loss is rapid during the first 4-6 months up to one year post SCI, with a $40 \%$ reduction in sublesional BMD reported by two years post injury. ${ }^{52}$ As opposed to other types of osteoporosis, which may affect all skeletal sites, SCI osteoporosis primarily affects sublesional areas that are weight bearing or rich in trabecular bone, such as the distal femur and the proximal tibia. Fractures occur twice as much in SCI than in non-SCI individuals and are more prevalent in the lower extremities. ${ }^{53} \mathrm{~A}$ significant proportion of individuals may experience spontaneous fracture, in the absence of trauma, at some point post injury (median time: 8.5 years). ${ }^{49}$ These fractures, mainly at the pelvis and lower extremities, add a significant burden to the quality of life of SCI individuals as they reduce mobility and independence, and increase the length of hospitalization. ${ }^{54}$ Higher rates of fractures are reported in SCI women, individuals with complete injury and individuals with paraplegia, the latter being more physically active and less dependent on assistance than individuals with tetraplegia, though with increased risk for falls. Given that SCI individuals experience an accelerated bone loss in the months following injury that is markedly greater than other types of disuse osteoporosis (for example, microgravity, bed rest), it is believed that immobilization has only a minor role in the pathogenesis of SCI-induced osteoporosis. Other factors related to neurological impairment, endocrine disorders and chronic inflammation, causing a decrease in skeletal anabolic factors (for example, testosterone, growth hormone, estrogens) and an increase in catabolic factors (for example, inflammatory cytokines), may also contribute to or aggravate the acute bone loss in SCI. ${ }^{55}$

Although osteoporosis is considered a multifactorial condition, vitamin $\mathrm{D}$ insufficiency is believed to act as a contributing factor. This occurs primarily through deregulation of calcium homeostasis with resulting secondary hyperparathyroidism and increasing bone resorption. Vitamin D and calcium supplementation has therefore been extensively studied in relation to BMD and fracture risk in populations other than SCI. Recent evidence from a meta-analysis of 4082 participants has reported no effect of vitamin D alone on BMD at any of the five anatomical sites investigated except for a slight effect at the femoral neck. ${ }^{56}$ The included interventions differed only in their vitamin D content; co-interventions (that is, calcium) were the same in all groups, which distinguishes the effect of calcium from that of vitamin D. Calcium supplementation suppresses bone remodeling, which exerts a beneficial effect on BMD. The effect of a calcium and vitamin $\mathrm{D}$ intervention on BMD may thus be a calcium effect. Alternatively, these results can also be interpreted as evidence that vitamin $\mathrm{D}$ requires concomitant calcium supplementation to positively affect the BMD.

The anti-fracture efficacy of vitamin $\mathrm{D}$ has been primarily documented in postmenopausal women and older individuals, as these segments of the population are more at risk for fracture. Bischoff-Ferrari et al. ${ }^{57}$ studied the efficacy of oral vitamin D supplementation in preventing non-vertebral and hip fractures among individuals aged 65 years and older. In their meta-analysis, which included 12 double-blinded randomized controlled trials (RCTs; total of 42279 individuals) for non-vertebral fractures and 8 RCTs for hip fractures (total of 40,886), they found a significant risk reduction for non-vertebral $(\mathrm{RR}=0.86,95 \% \mathrm{CI}, 0.77-0.96)$ but not for hip $(\mathrm{RR}=0.91,95 \% \mathrm{CI}, 0.78-1.05)$ fractures. To resolve the high heterogeneity among trials, they analyzed trials administering up to 400 IU from those given larger amounts (700-1000IU per day) separately. A significant anti-fracture efficacy of vitamin D was seen only in the high-dose trials with a $20 \%$ reduction in the risk for non-vertebral fractures $(\mathrm{RR}=0.80,95 \% \mathrm{CI}, 0.72-0.89)$ and a $18 \%$ decrease in the risk for hip fractures ( $R R=0.82,95 \%$ CI, 0.69-0.97). From these findings, we can conclude that doses less than 400 IU have no effect on fracture rates and doses greater than $700 \mathrm{IU}$ may be more beneficial in older individuals. This conclusion was later confirmed in another meta-analysis whereby the authors showed a reduction in the risk for both non-vertebral and hip fractures with the highest daily intake of vitamin D (median of $800 \mathrm{IU}$, range from 792 to $2000 \mathrm{IU}) .^{58}$ The effect of larger doses of vitamin D on fracture risk is currently unknown. One limitation of these meta-analyses is that they included trials that had studied vitamin $\mathrm{D}$ alone or in combination with calcium, thereby making it impossible to distinguish the anti-fracture effect of vitamin D alone. A recent Cochrane review has compared the effect of vitamin $\mathrm{D}$ alone vs no treatment/placebo to that of vitamin $\mathrm{D}$ and calcium vs no treatment/placebo on fracture risk in postmenopausal women and older men. ${ }^{59}$ Vitamin D taken alone did not reduce the risk for fractures as compared with no therapy or placebo. In contrast, the combination of calcium and vitamin D was more effective than no treatment or placebo as it slightly reduced the likelihood of hip $(\mathrm{RR}=0.84,95 \% \mathrm{CI}, 0.74-0.96)$, non-vertebral $(\mathrm{RR}=0.86,95 \% \mathrm{CI}$, $0.78-0.96)$ and any new fractures $(\mathrm{RR}=0.95,95 \% \mathrm{CI}, 0.90-0.99)$. The risk for vertebral fracture was not significantly reduced by vitamin $\mathrm{D}$ plus calcium ( $\mathrm{RR}=0.89,95 \% \mathrm{CI}, 0.74-1.09$ ).

In terms of fracture healing, only two studies have investigated the effect of calcium and vitamin D supplementation on this outcome. Doetsch et al. ${ }^{60}$ took serial BMD measurements of the shoulder over a 12 -week period in osteopenic or osteoporotic postmenopausal women with a proximal humerus fracture who were randomly assigned to receive daily $800 \mathrm{IU}$ of vitamin $\mathrm{D}_{3}$ and $1 \mathrm{~g}$ of calcium or placebo. Although both groups gained BMD during the healing process, the supplemented women experienced a higher increase than the placebo group. Yet, it remains difficult to ascribe this result to calcium, vitamin $\mathrm{D}$ or their combination. Serum calcium levels significantly increased in the supplemented women, which may lead to a higher calcium concentration in the bone microenvironment and facilitate fracture callus formation. Thirty-seven percent of the studied population had 25OHD levels below $30 \mathrm{nmol}^{-1}$ at baseline; yet, the authors did not 
report the vitamin D status distribution among the two groups at the start and end of the study. Therefore, we cannot conclude that the positive effect of the supplementation on callus formation results from the correction of the vitamin D insufficiency. In another study, Kolb et al. ${ }^{61}$ used peripheral quantitative computed tomography (pQCT) scanning to assess the fracture callus area of 94 postmenopausal with a distal radius fracture over a period of six weeks. All women received $880 \mathrm{IU}$ of vitamin $\mathrm{D}_{3}$ and $1 \mathrm{~g}$ calcium per day for this period. Their results highlighted that individuals with higher calcium levels prior to initiation of supplementation displayed higher fracture callus area after six weeks. In addition, women with initial vitamin D insufficiency did not differ in terms of fracture callus area at six weeks, indicating regular callus formation once calcium and vitamin $\mathrm{D}$ were substituted. From these findings, the authors concluded that normal calcium homeostasis is required for callus formation, emphasizing the importance of timely calcium and vitamin D supplementation.

Thus far, the impact of calcium and vitamin D supplementation on bone health, fracture risk and fracture healing has not been specifically studied in SCI individuals except for one placebo-controlled study, which has reported the effect of daily administration of the vitamin D analog, 1- $\alpha$-hydroxyvitamin $\mathrm{D}_{2}$, for 2 years on the BMD of the leg, spine and pelvis. ${ }^{62}$ Forty adults with long-lasting SCI (mean duration of $12 \pm 10$ years) were enrolled in this study, whereby the placebo and experimental group received $1.3 \mathrm{~g} \mathrm{~d}^{-1}$ of calcium and $800 \mathrm{IU} \mathrm{d}^{-1}$ of vitamin D. Although no difference was detected at the lumbar spine and pelvis, the use of the analog resulted in a $2 \%$ gain in leg BMD by 12 months, which was maintained until the end of the study period. Interestingly, supplemental calcium and vitamin $\mathrm{D}$ intakes in the placebo group did not significantly affect BMD at any site despite a comparable increase in $25 \mathrm{OHD}$ levels in both groups. In the absence of baseline rates of bone loss prior to study initiation, the lack of BMD change in placebo users did not suggest treatment failure. In fact, bone loss may have been worse without calcium and vitamin D.

In a small group of acute SCI individuals, Chen et al. ${ }^{63}$ used $0.5 \mu \mathrm{g} \mathrm{d}^{-1}$ of $1,25(\mathrm{OH})_{2} \mathrm{D}_{3}$ (that is, calcitriol) and $1250 \mathrm{mg}$ of calcium carbonate twice a day to treat bone hyper-resorption. After three days, they introduced intravenous pamidronate once daily for a total of 3 days (three doses of $30 \mathrm{mg}$ ). The combined calcitriol-calcium-pamidronate decreased bone resorption and calciuria and increased PTH and $1,25(\mathrm{OH})_{2} \mathrm{D}$ levels. However, study limitations included the very small number of subjects (that is, 21), the short study duration (that is, 2 weeks) and the occurrence of hypocalcemia in $44 \%$ of subjects after pamidronate administration. ${ }^{63}$ Clearly, more studies are needed to determine whether calcium and vitamin $\mathrm{D}$, alone or in combination with anti-osteoporosis agents and/or mechanical therapy, can prevent bone loss and fractures in SCI individuals.

Muscle. Vitamin D deficiency is associated with muscle weakness, myalgia and gait impairments, thereby suggesting that this vitamin has a prominent role in muscle health. ${ }^{64,65}$ Skeletal muscle is a physiological target of vitamin $\mathrm{D}$ actions as muscle cells not only express the VDR but are also endowed with 1- $\alpha$ hydroxylase, thus conferring them the ability to locally metabolize $25 \mathrm{OHD}$ to $1,25(\mathrm{OH})_{2} \mathrm{D}$. It is noteworthy that the presence of VDR and $1-\alpha$ hydroxylase in skeletal muscle has been shown in rodents and using the $\mathrm{C} 2 \mathrm{C} 12$ myoblast cell line, ${ }^{66,67}$ but remains controversial in humans. Some authors have detected the VDR in human skeletal muscle tissue, ${ }^{68}$ whereas others have not, ${ }^{69,70}$ and the presence of $1-\alpha$ hydroxylase has yet to be demonstrated. Interestingly, children with inherited 1- $\alpha$ hydroxylase deficiency have poor muscle tone and muscle weakness, features that are reversible with physiologic doses of $1,25(\mathrm{OH})_{2} \mathrm{D}_{3}{ }^{71,72}$ Proposed mechanisms include both genomic and non-genomic effects. ${ }^{73}$ Genomic actions lead to the modulation of muscle gene expression involved in myoblast proliferation and differentiation. For instance, $1,25(\mathrm{OH})_{2} \mathrm{D}$ was shown to exhibit antiproliferative effects by suppressing the expression of two myogenic regulatory factors, myogenin and $\mathrm{Myf5}$, in $\mathrm{C} 2 \mathrm{C} 12$ cells, a model frequently used to study skeletal muscle differentiation. ${ }^{66}$ In the same model, $1,25(\mathrm{OH})_{2} \mathrm{D}$ also downregulated the expression of myostatin, a negative regulator of skeletal muscle growth. In support of this are the observations made in the $V d r$ knockout mice, which display muscle fiber atrophy and impaired motor coordination, independent of changes in calcium and phosphate homeostasis ${ }^{69,74-76}$ A strong induction in the expression of $V d r$ and CYP27B1 was also observed following local muscle injury, thereby suggesting that vitamin $\mathrm{D}$ is involved in muscle regeneration and repair. ${ }^{76}$ Vitamin D can elicit rapid cellular responses in muscle that are not mediated by transcriptional mechanisms. These non-genomic effects include calcium influx into the muscle cells, relevant to muscle contraction. The increase in intracellular calcium also enhances glucose transporter 4 (GLUT4) translocation to the cell membrane, thus providing energy substrates for muscle function. ${ }^{65,77}$

Many studies have examined the relationship between vitamin D and measures of physical performance and physical function. Vitamin $\mathrm{D}$ has been extensively studied in relation to muscle strength, but less with respect to muscle mass and power. ${ }^{78}$ Overall, observational studies were more likely to report positive associations between 25OHD levels and muscle strength or physical performance than intervention studies. ${ }^{77}$ In a systematic review performed on healthy adults (that is, $18-65$ years), Redzic el al. ${ }^{79}$ reported a positive association between 25OHD levels and muscle strength. This association appears stronger in older individuals and in more vulnerable populations, such as the institutionalized or hospitalized, with deficient $\left(<25 \mathrm{nmoll}^{-1}\right)$ or insufficient $\left(<50 \mathrm{nmol} \mathrm{l}^{-1}\right)$ vitamin D status. By contrast, the association was no longer observed when baseline vitamin $\mathrm{D}$ status was higher $\left(>65-75 \mathrm{nmoll}^{-1}\right)$ and in younger people. ${ }^{80}$ In addition, individuals who presented a change in circulating $25 \mathrm{OHD}>50 \mathrm{nmol}^{-1}$ from baseline following vitamin D supplementation were more likely to benefit from the effect of vitamin $\mathrm{D}$ on muscle strength. ${ }^{78}$ Vitamin D supplementation did not affect muscle mass and power, although the number of studies on these outcomes remains limited. ${ }^{81-83}$ Collectively, the supporting evidence for a beneficial effect of vitamin D on muscle function remains weak owing to the multiplicity of measures using various methods and the lack of unequivocal improvements in outcomes following vitamin D supplementation.

Following SCI, immobilization and endocrine disturbances, such as reduced IGF-1 and testosterone levels, markedly decrease muscle mass. ${ }^{84}$ In addition, physiological changes to muscle fibers are reported 4 to 7 months after injury with a shift in the predominance of slow type I fibers to fast type II fibers with time post injury. ${ }^{85}$ Interestingly, a previous study suggested a potential selective effect of vitamin D supplementation (that is, 4000 IU per day) on type II fibers with an overall gain in fiber size in older women. ${ }^{86}$ Thus far, very few studies have been conducted on SCI, muscle and vitamin D. In rats, in which peripheral or central nerve injury was performed to mimic SCI, administration of high doses of vitamin $\mathrm{D}_{3}\left(500 \mathrm{IU} \mathrm{kg}^{-1} \mathrm{~d}^{-1}\right)$ a few hours post insult resulted in significant improvements in locomotion and spasticity. ${ }^{87,88}$ Of note, rats receiving vitamin $\mathrm{D}_{3}$ shortly after the injury showed better outcomes compared with lesioned rats, which 
were given vitamin $\mathrm{D}_{3}$ seven days post injury. Although extrapolations of these findings to the clinical setting may be tempting, interventional studies aimed at investigating the effects of vitamin D supplementation on functional recovery should be undertaken. In a cohort of 100 chronic SCI individuals, Barbonetti et al. ${ }^{89}$ were the first to report an independent positive association between 25OHD levels and overall physical function outcomes. They found that lower 25OHD levels were associated with lower functional independence degree in activities of daily living (ADL) and poorer engagement in leisure time physical activity (LTPA). To preserve neurological function and minimize the damages following traumatic SCI, Aminmansour et al. ${ }^{90}$ randomly assigned SCI individuals within $8 \mathrm{~h}$ of injury to placebo or oral vitamin $\mathrm{D}_{3}\left(5 \mu \mathrm{g} \mathrm{kg}^{-1}\right)$ and intramuscular progesterone $\left(0.5 \mathrm{mg} \mathrm{kg}^{-1}\right)$ twice daily for up to 5 days. Neurologic function was assessed using the motor and sensory ASIA scores 6 days and 3 and 6 months after the injury. Although motor and sensory scores significantly improved after 6 months in both groups, the scores were higher in the vitamin D-progesterone group than in the placebo group, particularly in those who received the treatment within $4 \mathrm{~h}$ of injury. Nevertheless, given the absence of a group receiving progesterone and vitamin $\mathrm{D}_{3}$ alone, one cannot conclude, based on these findings, that vitamin $\mathrm{D}$ promotes neurological and functional recovery in SCI.

\section{Cardiometabolic health}

Cardiometabolic health and vitamin D has recently emerged as a new area of investigation. Cardiometabolic risk factors include hypertension, obesity, dyslipidemia, glucose intolerance and diabetes. This section will briefly outline potential vitamin $\mathrm{D}$ mechanisms of action as well as associations between vitamin $\mathrm{D}$ and cardiometabolic risks factors, cardiovascular disease (CVD) and metabolic syndrome (MeS) with special reference to SCI.

Vitamin D and hypertension. The effect of vitamin D on blood pressure was suggested to be related to its suppressive actions on the renin-angiotensin-aldosterone system, ${ }^{91}$ inhibition of hyperparathyroidism, direct actions on the vessel wall and protection from oxidative stress. ${ }^{92} V d r$-deficient mice have increased blood pressure, which is mediated by renin and plasma angiotensin II elevation. Interestingly, these alterations appear independent from changes in serum calcium and PTH and are reversed by $1,25(\mathrm{OH})_{2} \mathrm{D}$ supplementation, which is thought to act through a VDR-dependent mechanism by lowering renin activity. ${ }^{93}$ Vitamin D deficiency is often accompanied by secondary hyperthyroidism as a result of low serum levels of ionized calcium. PTH exerts direct effects on the cardiovascular system by acting on vascular smooth muscle cells and increasing arterial stiffness. ${ }^{94}$ Endothelial and vascular smooth muscle cells express both VDR and 1- $\alpha$ hydroxylase, which make them a target for vitamin $\mathrm{D}$ actions. In endothelial cells, $1,25(\mathrm{OH})_{2} \mathrm{D}$ has vasoprotective properties that increase the activity of the endothelial nitric oxide synthase, decrease the expression of endothelial adhesion molecules and have anti-inflammatory actions. In vascular smooth muscle cells, $1,25(\mathrm{OH})_{2} \mathrm{D}$ exerts vasodilatory effects and mediates proliferation, differentiation and migration of these cells, thereby having antiatherosclerotic effects. Although biological plausibility appears strong, clinical studies have failed to provide compelling evidence on the effectiveness of vitamin D as an antihypertensive compound.

Clinical studies on vitamin D and blood pressure were conducted in diverse populations (that is, different ages, with or without prior hypertension and with or without underlying health conditions such as diabetes and kidney or cardiovascular disease). Most large sample size cross-sectional studies have found an inverse association between vitamin D status and blood pressure. ${ }^{94,95}$ However, these findings have not been firmly confirmed by RCTs. A recent meta-analysis of RCTs has reported that vitamin D supplementation had no effect on blood pressure. ${ }^{96}$ However, a reduction $(\approx 1.3 \mathrm{~mm} \mathrm{Hg})$ of the diastolic blood pressure was reported on subgroups with pre-existing cardiometabolic disease, ${ }^{97}$ although others have not observed such association. ${ }^{96}$ Other recent RCTs also failed to show the antihypertensive effect of vitamin D supplementation. ${ }^{98,99}$

Blood pressure is correlated to the level of injury in SCI individuals whereby cervical and high thoracic injuries are associated with autonomic involvement with unstable blood pressure and coexisting episodes of orthostatic hypotension and autonomic dysreflexia. ${ }^{100}$ In the chronic phase, individuals with tetraplegia are more prone to hypotension, whereas paraplegic individuals are more likely to have hypertension. ${ }^{43,101}$ Whether vitamin D supplementation is effective in lowering blood pressure in paraplegia or whether it will be detrimental to individuals with tetraplegia, or in cases of autonomic dysreflexia, has not yet been studied.

Vitamin D and dyslipidemia. Suggested mechanisms linking vitamin $\mathrm{D}$ and lipids are either direct or indirect through regulation of calcium and PTH homeostasis. Studies on $V d r$ knockout mice provide interesting leads regarding direct actions of vitamin $\mathrm{D}$ on lipid metabolism. These mice display reduced plasma levels of triglycerides (TG) and cholesterol consequent to increased energy expenditure and lipolysis. ${ }^{102}$ By regulating calcium intestinal absorption, vitamin D indirectly affects lipid absorption. In the intestine, calcium, fatty acids and bile acids form insoluble soaps that are excreted in the stool. ${ }^{103}$ One would then expect that high levels of vitamin D would enhance calcium absorption and result in less calcium in the intestinal lumen and more fat absorbed. Nevertheless, the effect of calcium on fat absorption appears relatively modest and may be too small to affect serum lipids. Finally, through the maintenance of serum calcium and the ensuing suppression of PTH secretion, vitamin D may indirectly regulate lipolysis as PTH was shown to inhibit this process in vitro. ${ }^{104,105}$

The majority of observational studies found associations between 25OHD levels and a favorable serum lipid profile, particularly HDL-cholesterol and TG levels, whereas the results were less consistent for LDL- and total cholesterol. ${ }^{106,107}$ Maki et al. ${ }^{107}$ concluded that each $2.5 \mathrm{nmoll}^{-1}$ increase in 25OHD level resulted in an elevation of $0.42 \mathrm{mg} \mathrm{dL}^{-1}$ of HDL and suggested that an inverse dose-dependent relationship existed between 25OHD and TG levels. The health benefits of high $25 \mathrm{OHD}$ concentration reported in observational studies were, however, not reproduced in RCTs. Following vitamin D supplementation, no clear improvement in the serum lipid profile was observed, with reports of higher, unchanged or lower concentration of lipid fractions. ${ }^{106,108-110}$ Such discrepancies could not be ascribed to doses administered, duration of supplementation, or to features of the population study, and most likely arose from a lack of appropriate statistical power. Future adequately powered studies are therefore warranted to firmly establish the positive impact of vitamin D on serum lipids.

SCI individuals exhibit a unique atherogenic lipid profile characterized by reduced HDL- and total cholesterol levels, which result in an elevated total to HDL cholesterol ratio. ${ }^{111,112}$ In the general population, the ratio of total to HDL-cholesterol is the strongest predictor of ischemic heart disease mortality, being twice as informative as total cholesterol alone. ${ }^{113}$ Interestingly, 25OHD levels were found to be negatively associated with this ratio. ${ }^{114,115}$ 
Changes in lipid profile are highly associated with the degree of neurological impairment; patients with lower motor score and greater neurological level of injury display the lowest values of HDL- and total cholesterol. ${ }^{116}$ These changes can be attributed to several factors. Physical activity is generally known to increase HDL-cholesterol; reduced physical activity due to limited mobility may therefore contribute to the low HDL-cholesterol. A dysfunctional autonomic nervous system, which increases the risk for obesity by reducing the resting metabolic rate, may also negatively affect serum lipids. Finally, post-injury dietary intakes, with potential risk for under- or overnutrition, may lead to the development of an atherogenic lipid profile. It is currently unknown whether vitamin D supplementation would improve the blood lipid profile of SCI individuals.

Vitamin D and glucose metabolism: glucose intolerance or diabetes. Nearly four decades ago, Norman et al. ${ }^{117}$ demonstrated that pancreases isolated from rats made vitamin $\mathrm{D}$ deficient by nutritional means exhibited reduced insulin secretion, which was normalized by vitamin D repletion. Interestingly, normalization of serum calcium concentration with dietary calcium did not restore the blunted insulin secretion of these D-deficient rats, which is in contrast with another report. ${ }^{118}$ Intracellular calcium is important for insulin exocytosis and it is suggested that vitamin $\mathrm{D}$, by maintaining normal extracellular calcium, ensures that sufficient calcium is available to fill intracellular pools required for optimal insulin release. Later on, it was shown that pancreas islets, including beta cells, express VDR and $1-\alpha$ hydroxylase. ${ }^{119}$ Accordingly, $V d r$-mutant mice displayed increased blood glucose and depressed insulin levels in response to a glucose challenge, in spite of normal $\beta$-cell mass and unaltered size and number of pancreatic islets. ${ }^{120}$ The presence of $1-\alpha$ hydroxylase suggests an autocrine or paracrine action of circulating 25OHD on beta cells.

There is some evidence that vitamin $\mathrm{D}$ modulates insulin action through its ability to reduce PTH levels. It is postulated that increased PTH is associated with reduced insulin sensitivity. The secondary hyperparathyroidism that often accompanies vitamin D deficiency may therefore explain some of the effects of an impaired vitamin D status on insulin secretion and sensitivity. ${ }^{121}$ Another mechanism by which vitamin $\mathrm{D}$ may affect insulin action is through the transcriptional regulation of the insulin receptor, whose promoter contains a vitamin $\mathrm{D}$ response element consensus sequence. In vitro studies have shown that a pharmacological dose of $1,25(\mathrm{OH})_{2} \mathrm{D}_{3}$ upregulated the mRNA and protein expression of the insulin receptor, which translated into a greater insulin-induced glucose transport. ${ }^{122}$ Among other mechanisms, vitamin D may modulate insulin sensitivity through its effect on skeletal muscle cells by mechanisms not yet defined. Indeed, it has been demonstrated that $1,25(\mathrm{OH})_{2} \mathrm{D}_{3}$ dose-dependently improved free fatty acid-induced insulin resistance in $\mathrm{C} 2 \mathrm{C} 12$ myoblasts. ${ }^{123}$ Altogether, these studies support both direct and indirect biological roles for vitamin $\mathrm{D}$ in insulin secretion and sensitivity.

Cross-sectional studies on large populations found consistent inverse associations between serum 25OHD and diabetes risk. In the Third National Health and Nutrition Examination Survey (NHANES), a cohort representative of the U.S. adult population, Scragg et al. ${ }^{124}$ reported an inverse association between serum 25OHD and diabetes risk among non-Hispanic Caucasians and Mexican Americans, but not in non-Hispanic African Americans. Non-Hispanic Caucasians with levels $\geqslant 81.0 \mathrm{nmoll}^{-1}$ exhibited a 75 and $72 \%$ risk reduction of diabetes as defined by fasting and $2 \mathrm{~h}$-glucose, respectively.
Similar associations were observed in large population-based studies worldwide. ${ }^{125-127}$

Prospective observational studies also reported an inverse association between 25OHD levels and incident diabetes in populations without prior diabetes or glucose intolerance. In their meta-analysis, including 21 prospective studies and a total of 76,220 participants, Song et al. ${ }^{128}$ found a $38 \%$ risk reduction in developing type 2 diabetes in the highest category of $25 \mathrm{OHD}$ levels $(\mathrm{RR}=0.62$; 95\% CI, 0.54-0.70). Similarly, Afzal et al. ${ }^{129}$ meta-analyzed 14 prospective studies (72,440 participants) and found that individuals in the lowest quartile of $25 \mathrm{OHD}$ concentration had a $50 \%$ increased risk of developing type 2 diabetes $(\mathrm{OR}=1.50 ; 95 \% \mathrm{CI}, 1.33-1.70)$ compared with the top quartile. In the largest meta-analysis thus far, which covered 18 studies involving 210,107 participants with nearly 16,000 incident metabolic cases, Khan et al ${ }^{130}$ found a risk ratio of 0.81 (95\% CI, 0.71-0.92) for the top third vs the bottom third of baseline 25OHD levels. Tsur et al. ${ }^{131}$ further added to this association by showing that low serum $25 \mathrm{OHD}$ concentration (that is, $\leqslant 25 \mathrm{nmoll}^{-1}$ ) was associated with an increased risk for progressive glucose intolerance and diabetes compared with serum 25OHD $\geqslant 75 \mathrm{nmoll}^{-1}$. However, observational studies have limitations, including the presence of residual and unmeasured confounding, the limited ability to infer causality and the risk for potential reverse causation, meaning that reduced $25 \mathrm{OHD}$ levels may be a consequence, rather than a cause, of an underlying subclinical glucose intolerance.

Despite biological plausibility and consistent evidence from observational studies, results from vitamin D supplementation trials have been disappointing. Although some studies have shown improvements in glucose metabolism, insulin secretion and insulin sensitivity in populations with various degrees of glucose tolerance, ${ }^{132-136}$ studies targeting vulnerable groups such as vitamin D-deficient adults with diabetes or at high risk of developing diabetes have failed to find improvements in such outcomes. ${ }^{137,138}$ These negative results may be attributed to too short a duration of the treatment, too small a dose or inclusion of vitamin D-sufficient subjects. To overcome such limitations, Davidson et al. ${ }^{137}$ randomized vitamin D-deficient adults - mostly Latinos and African Americans- with impaired glucose tolerance to weekly placebo or vitamin $\mathrm{D}_{3}$ with doses based on weight and baseline vitamin $\mathrm{D}$ status. The mean weekly dose of vitamin $\mathrm{D}_{3}$ was $88865 \mathrm{IU}$ and the goal of such supplementation was to achieve 25OHD levels between 163 and $225 \mathrm{nmoll}^{-1}$. After one year of supplementation and the achievement of a mean 25OHD level of $175 \mathrm{nmoll}^{-1}$, no difference was seen between the placebo and the supplemented group for any of the outcomes related to insulin secretion and sensitivity. Although this study reports negative findings, Pilz et al. ${ }^{139}$ rightly pointed out that at least it provides crucial data regarding the safety of taking high doses of vitamin D for 1 year and of maintaining a high level of $25 \mathrm{OHD}$ in a population that should most likely benefit from such supplementation.

It has been consistently demonstrated that individuals with SCI display hyperinsulinemia and insulin resistance. Contributing factors involve body composition changes, intramuscular fat accumulation, which interferes with glucose metabolism, lower physical activity and hormonal changes. ${ }^{140,141}$ In addition, post-lesion changes in muscle metabolism, such as reduced GLUT4 expression and alterations in muscle fiber composition, can also negatively impact insulin sensitivity. The relationship between vitamin D status and glucose metabolism as well as the impact of its supplementation has never been studied within SCI individuals. 
d. Obesity. Obesity is consistently associated with lower 25OHD levels and poor vitamin D status. Using a bi-directional Mendelian randomization analysis, Vimaleswaran et al. ${ }^{142}$ concluded that higher BMI led to lower 25OHD levels, but not the other way around, thereby providing evidence of a one-directional, causal relationship between these two outcomes. On the other hand, the presence of VDR and 1- $\alpha$ hydroxylase in the adipocytes strongly suggests that vitamin D also exerts direct actions on fat cells. However, in vitro findings are inconsistent between cell models and species. In 3T3-L1 cells, a mouse preadipocyte cell line, $1,25(\mathrm{OH})_{2} \mathrm{D}_{3}$, exerts anti-adipogenic effects by inhibiting their differentiation ${ }^{143}$ whereas in primary mouse adipocytes and human preadipocytes it promotes adipogenesis. ${ }^{144}$ Alternatively, the increased PTH levels that normally accompany decreased concentration of $25 \mathrm{OHD}$ may have a role in lipogenesis through the increase of intra-adipocyte calcium levels, which in turn may enhance the expression of the lipogenic enzyme fatty acid synthase. $^{145}$

Despite the consistent inverse association reported between 25OHD levels and BMI, interventional studies assessing the impact of supplemental vitamin D on BMI or body fat changes have been conflicting. It should be pointed out that BMI cannot distinguish between lean and fat mass, and therefore BMI variations may not accurately reflect changes in fat mass or specific adipose tissue compartments. In a meta-analysis, Mora et al. ${ }^{146}$ combined nine RCTs including 1651 obese adults to assess the effects of supplemental vitamin D on BMI changes. The selected studies varied in terms of baseline assessment of 25OHD levels as well as supplementation regimens (that is, with or without calcium), trial durations (that is, 6-196 weeks) and dosage (that is, 200-1110 IU). Only five studies reported beneficial effects of vitamin D supplementation, whereas four studies had no impact, which led the authors to conclude that vitamin D supplementation did not significantly affect BMI change. More recently, in a meta-analysis including 26 RCTs and 42430 adults, Chandler et al. ${ }^{147}$ found no evidence of an impact of vitamin D supplementation on weight, BMI and fat mass. Overall, current evidence does not support a beneficial effect of vitamin D supplementation on weight or fat loss, and studies using more accurate measures of body composition, such as DXA, are warranted.

Obesity is a major concern for SCI individuals. A large proportion of patients experience weight gain after their lesion. Reduced physical activity, lower resting energy expenditure due to changes in body composition and hormonal changes are all contributing factors. To date, no prospective or controlled trial studies have specifically investigated the association between vitamin $\mathrm{D}$ status and body composition of SCI individuals.

Vitamin $D$ and cardiovascular disease. Although the association between vitamin $\mathrm{D}$ and single cardiometabolic risk factors appears plausible, it may not translate into increased cardiovascular events (for example, stroke, angina pectoris and myocardial infarction) and mortality. It is thus important to consider those aspects in relation to vitamin $\mathrm{D}$ as well.

Wang et al. ${ }^{148}$ carried out a meta-analysis on a pool of 19 prospective, yet highly heterogenous, studies including $6123 \mathrm{CVD}$ cases and 65,994 participants. They reported an inverse association between total CVD risk and 25OHD concentration with a pooled RR of 1.52 (95\% CI, 1.3-1.77) when comparing individuals with the lowest 25OHD levels with those with the greatest. Associations of similar magnitude were found with CVD mortality (RR 1.42; 95\% CI, $1.19-1.71$ ), coronary heart disease (RR $1.38 ; 95 \% \mathrm{CI}, 1.21-1.57$ ) and stroke (RR 1.64; 95\% CI, 1.27-2.10). Using a dose-response approach, they also reported a linear increase in CVD risk with decreasing $25 \mathrm{OHD}$ levels over the range of 20-60 $\mathrm{nmol}^{-1}$, whereas there was no significant effect on CVD risk with 25OHD concentration above $60 \mathrm{nmoll}^{-1}$. More recently, in an analysis of the results from the ESTHER study, a large German population-based cohort study including older adults, Perna et al. ${ }^{149}$ studied the association between 25OHD levels and CVD by distinguishing between fatal and non-fatal events. They reported a $27 \%$ increased risk for total CVD in individuals with vitamin $\mathrm{D}$ deficiency $\left(<30 \mathrm{nmoll}^{-1}\right)$ compared with those with levels $\geqslant 50 \mathrm{nmoll}^{-1}$, with a much stronger risk increase for fatal than for non-fatal CVD events. The authors suggested two explanations for such findings: that low 25OHD levels affected the course, not the occurrence of CVD events, or, alternatively, that the association between low serum 25OHD and mortality may have been driven by residual confounding. It has been postulated that the relationship between vitamin $\mathrm{D}$ status and cardiovascular health is obscured by the fact that $25 \mathrm{OHD}$ levels may be a marker of baseline health as less healthy individuals tend to spend less time outside, be exposed to less UV-B radiation and thus present with lower serum 25OHD. ${ }^{150}$ The strong confounding effect of baseline health may therefore account for the positive associations found in epidemiological studies.

Although findings of observational studies support the conduct of RCTs with cardiovascular outcomes as the primary end point, evidence from clinical trials remains limited. Thus far, most studies have explored the impact of calcium and vitamin D supplementation on bone health and risk for fracture as primary outcomes, while looking at cardiovascular events as secondary end points. The largest trial to date, the Women's Health Initiative (WHI), randomized a large cohort of healthy postmenopausal women to receive $400 \mathrm{IU}$ vitamin D plus $1 \mathrm{~g}$ calcium carbonate or matching placebo. ${ }^{151}$ After seven years of follow-up, the authors concluded that the combined calcium and vitamin $\mathrm{D}$ supplementation did not affect the risk for any of the cardiovascular end points studied, including myocardial infarction, stroke and coronary heart disease mortality. Wang et al. ${ }^{152}$ subsequently meta-analyzed 8 RCTs to assess whether calcium and vitamin D supplements reduce the risk for cardiovascular events in adults. Vitamin D supplementation trials did not significantly reduce the risk for CVD, with risk ratios of 0.90 (95\% CI, 0.77-1.05) and 1.04 (95\% CI, 0.92-1.18) for vitamin D supplements vs placebo and combined calcium and vitamin D vs double placebo, respectively. In a more recent meta-analysis, Ford et al. ${ }^{153}$ found that vitamin D supplementation had no significant effect on the risk for myocardial infarction, stroke or cardiac failure. Limitations to vitamin D supplementation trials often include the use of a too low dose to produce clinically relevant effects, the use of concomitant calcium supplementation and the lack of consideration of baseline concentration of 25OHD. In fact, vitamin D supplementation of individuals with lower $25 \mathrm{OHD}$ levels is more likely to produce a measurable benefit. If basal vitamin D status of enrolled participants varies from individual to individual it may lead to different individual responses to supplementation, thus resulting in a null effect. Several large RCTs (for example, the Vitamin D Assessment Trial (ViDA), the Vitamin D and Omega-3 Trial (VITAL) and the Finnish Vitamin D Trial), sufficiently powered to detect a potential effect of higher doses of vitamin D supplementation on cardiovascular events as primary outcomes, are currently ongoing, and results are expected in the coming years. Although these trials were intended to overcome the limitations related to previous RCTs (that is, too low a dose, the lack of baseline measurement of 25OHD levels and cardiovascular end points as secondary outcomes), they did not set vitamin D deficiency as 
an inclusion criterion and some of them allowed nonprotocol supplements of calcium and vitamin D.

CVD is now the leading cause of death in individuals with SCI who survived their injury. The odd ratios for CVD and stroke are estimated to be 2.72 (95\% CI, 1.94-3.82) and 3.72, (95\% CI, 2.22-6.23), respectively, in SCI vs able-bodied individuals. ${ }^{154-156}$ As SCI individuals develop cardiovascular risk factors at an earlier stage compared with non-SCI individuals, and live longer, any intervention reducing the burden of CVD, even with moderate results, could be clinically attractive. Thus far, the relationship between vitamin D status and cardiovascular health among spinal cord-injured individuals has not been investigated, nor have studies been conducted to assess the impact of vitamin D supplementation on cardiovascular outcomes in this population.

Vitamin $D$ and metabolic syndrome. $\mathrm{MeS}$ is a particular combination of phenotypes, primarily related to glucose metabolism (for example, insulin sensitivity, fasting glucose and glucose tolerance), lipid profile (for example, TG and HDL levels), blood pressure and visceral adiposity, which confers an increased risk for CVD and diabetes.

In one of the first meta-analyses looking at the association between 25OHD levels and cardiometabolic health, Parker et al. ${ }^{157}$ reviewed 28 studies including 99745 participants, among which 8 had MeS as the main outcome. They found that high $25 \mathrm{OHD}$ levels were associated with a $51 \%$ reduction in the prevalence of MeS (OR: $0.49 ; 95 \% \mathrm{CI}$, 0.38-0.64). A recent dose-response meta-analysis aimed at examining the association between 25OHD levels and the risk for MeS among adults from the general population reported a $13 \%$ decrease in risk (RR: 0.87 ; 95\% CI, $0.83-0.92$ ) per $25 \mathrm{nmol}^{-1}$ increment in blood 25OHD. This protective effect was seen in cross-sectional but not in longitudinal studies, whereby the risk ratio was equal to 1.0 (95\% CI, $0.98-1.02$ ), a result that may arise from the fact that only two longitudinal studies were included in the analyses. ${ }^{130,158}$ The issue of causality therefore remains an important knowledge gap with regard to MeS and vitamin D as no large RCT of vitamin D supplementation has been carried out with MeS incidence as the primary outcome.

In non-SCI individuals, prevalence of $\mathrm{MeS}$ varies depending on the definition used to define MeS. ${ }^{159-161}$ Whereas some SCI authors have used the $\mathrm{WHO}^{162}$ or the American Heart Association definition, ${ }^{163}$ others have used the definition of th National Cholesterol Education Program-Adult Treatment Panel (NCEP-ATP). ${ }^{164-166}$ To reflect the changes in body composition seen in SCI individuals, authors have either modified (for example, cutoff BMI of 22, ${ }^{101}$ population-specific abdominal circumference ${ }^{166}$ ) or introduced (visceral body fat ${ }^{166}$ ) criteria to the existing non-SCI MeS definitions. For instance, some authors have argued that a waist circumference cutoff of $94 \mathrm{~cm}$ should be used instead of the $102 \mathrm{~cm}$ used in non-SCI individuals. ${ }^{167}$ It remains therefore difficult to accurately compare the prevalence of MeS between SCI and the able-bodied population given the differences in the criteria used to identify individuals with MeS. Furthermore, risk factors may vary according to the level of injury. ${ }^{101}$ However, most authors agree that SCI individuals exhibit higher MeS prevalence, estimated to be $22.6 \%$, compared with the general population ${ }^{156,164,165,168,169}$ Factor analysis reveals that risk clustering in SCI individuals may differ compared with that in the able-bodied population. ${ }^{101,162}$ Indeed, Liang et al. ${ }^{163}$ comparing SCI men with age- and race-matched able-bodied controls found no difference in MeS prevalence, which led them to suggest that distinct risk factor patterns, rather than MeS per se, contribute to the increased rate of CVD and diabetes seen in SCI individuals.

\section{CONSIDERATIONS FOR VITAMIN D SUPPLEMENTATION}

There are currently two ways to improve vitamin D status: increase sun or UVB exposure with its inherent risks or encourage intakes of vitamin D. Given the low number of foods containing large amounts of vitamin D and the sun avoidance that is recommended for most SCI individuals, supplementation may remain the sole route to ensure enough vitamin D intake to maintain circulating 25OHD D in the optimal range. However, a few considerations should be taken into account prior to prescribing vitamin $\mathrm{D}$ supplements. The reader is referred to a recent review for a detailed description of the demographic and environmental factors that may impact the individual response to vitamin D supplementation. ${ }^{170}$ Some of them are briefly reviewed here with a special reference to SCI individuals when appropriate.

\section{Clinical threshold for vitamin D sufficiency}

Although the cutoff value for absolute vitamin D deficiency (25OHD levels $<25 \mathrm{nmoll}^{-1}$ ) appears consensual among the scientific community, definitions for vitamin D insufficiency and adequacy still represent a matter of debate. This lack of consensus represents a barrier to determine who should be screened and when, who would benefit from supplementation, when to initiate supplementation as well as the dosage and the dosing strategy. A number of clinical guidelines and position statements as well as dietary recommendations have been reported to define the optimal vitamin $\mathrm{D}$ status and how to reach and maintain vitamin D sufficiency. ${ }^{171,172}$ However, the lack of consensus between two important key players, namely the Institute of Medicine (IOM) and the Endocrine Society, has led to considerable confusion among practitioners. ${ }^{172}$ It should be underscored that the two reports are intended for different populations: the general population for the IOM and individuals at risk for deficiency for the Endocrine Society. Nevertheless, the Endocrine Society produced a list of indications for vitamin D screening from which SCI is absent. The IOM recognizes that $25 \mathrm{OHD}$ levels greater than $50 \mathrm{nmoll}^{-1}$ are indicative of vitamin D sufficiency, as those are associated with PTH normalization, reduced risk for osteomalacia and optimal bone and muscle function. In order to maximize the non-skeletal effects of vitamin D, the Endocrine Society claims that vitamin D sufficiency is achieved with $25 \mathrm{OHD}$ levels greater than $75 \mathrm{nmoll}^{-1}$ and that vitamin $\mathrm{D}$ deficiency is defined by levels below $50 \mathrm{nmoll}^{-1}$. Observational studies have shown that serum 25OHD greater than $75 \mathrm{nmoll}^{-1}$ is associated with a decreased risk of many disorders including certain types of cancer and autoimmune and cardiovascular diseases. However, RCTs have not consistently confirmed these associations. ${ }^{173}$

The latest recommendations from the European Society for clinical and economic aspects of osteoporosis and osteoarthritis are more nuanced. ${ }^{171}$ They state that there is a risk for adverse outcomes at $25 \mathrm{OHD}$ levels below $50 \mathrm{nmol}^{-1}$, whereas above that level there is no clear consensus for additional beneficial effects. Decision to supplement should be made on an individual basis taking into account factors such as age, severity of disease, kidney function, $\mathrm{BMI}$ and baseline 25OHD values. Targeting 25OHD levels greater than $75 \mathrm{nmoll}^{-1}$ may be beneficial to individuals at higher risk for fracture, but will require higher dosage and a more regular monitoring of 25OHD level.

\section{Individual variability}

The level of $25 \mathrm{OHD}$ achieved after vitamin D supplementation varies widely among individuals, which complicates the process of selecting the right dose of vitamin $\mathrm{D}$ to reach a target $25 \mathrm{OHD}$ level. Subject 
characteristics including BMI and the baseline level of 25OHD, which are inversely correlated with change in $25 \mathrm{OHD}$, may contribute to this variability. In addition, genetic variants may influence not only 25OHD baseline levels but also the increment in response to a given dose of vitamin D. ${ }^{152,174,175}$ A genome-wide association study that included more than 30000 Caucasians revealed that four genes contribute to the interindividual variability in $25 \mathrm{OHD}$ levels. ${ }^{152}$ These genes encode for proteins involved in vitamin $\mathrm{D}$ metabolism: dehydrocholesterol reductase, responsible for the availability of the vitamin $\mathrm{D}_{3}$ precursor 7 -dehydrocholesterol in the skin; $\mathrm{DBP}$, the main serum carrier of vitamin D; and CYP2R1 and CYP24A1, two cytochromes involved in the conversion of vitamin D into 25OHD and the degradation of $25 \mathrm{OHD}$ and $1,25(\mathrm{OH})_{2} \mathrm{D}$, respectively. ${ }^{6}$ Interestingly, in a recent Danish study, the authors reported that common genetic variants of the same genes, namely CYP2R1 and $G C$, which encode the DBP, influence $25 \mathrm{OHD}$ response to UVB artificial radiation and intake of vitamin $\mathrm{D}_{3}$-enriched foods. ${ }^{176}$ Although these results are promising, it remains currently unknown whether these variants should be taken into consideration when prescribing vitamin D supplements. Nevertheless, taken together, these studies have strong implications for public health, as some individuals may need personalized vitamin D recommendations based on their genetic makeup.

\section{$\mathrm{D}_{2}$ vs $\mathrm{D}_{3}$}

Given that vitamin $\mathrm{D}_{3}$ and $\mathrm{D}_{2}$ differ only by the structure of their side chains, it is theoretically assumed that the body uses them in an identical manner. Although both forms are processed similarly, there has been much debate as to whether vitamin $\mathrm{D}_{3}$ or $\mathrm{D}_{2}$ are equivalent in their ability to raise $25 \mathrm{OHD}$ level. ${ }^{177-179} \mathrm{~A}$ recent meta-analysis revealed that $\mathrm{D}_{3}$, either given in large intermittent bolus or daily small doses, is more proficient in raising $25 \mathrm{OHD}$ than is $\mathrm{D}_{2}{ }^{180}$ These findings are explained by the fact that $\mathrm{D}_{3}$ and $\mathrm{D}_{2}$ exhibit important differences at the level of their metabolism. $\mathrm{D}_{3}$ is the preferred substrate for the hepatic 25-hydroxylase, which converts $\mathrm{D}_{3}$ and $\mathrm{D}_{2}$ to their respective $25 \mathrm{OHD}$, and display higher affinity for the DBP. These biological qualities may allow $\mathrm{D}_{3}$ to be efficacious for a longer time and at greater concentration than $\mathrm{D}_{2}$.

\section{Dosing regimens}

The half-life of $25 \mathrm{OHD}$ is approximately 21 days, which makes it suitable for intermittent dosing regimens. Although the attainment of similar 25OHD levels is demonstrated upon the administration of the same cumulative dose of vitamin $\mathrm{D}_{3}$ either daily (1500 IU), weekly (10 $500 \mathrm{IU}$ ) or monthly (45 $000 \mathrm{IU})$, the pharmacokinetics was shown to differ between the three regimens. ${ }^{181}$ Monthly bolus of vitamin $\mathrm{D}_{3}$, as opposed to a daily or weekly regimen, induced a significant elevation of $25 \mathrm{OHD}$ within the first $24 \mathrm{~h} .{ }^{181}$ Furthermore, fluctuation of $25 \mathrm{OHD}$ levels, characterized by the attainment of a peak within the first week followed by a slow decline thereafter, is more likely to occur with a monthly regimen. ${ }^{182}$ The biological impact of such fluctuations is unclear and warrants further exploration. On the other hand, patients prefer less frequent dosing as it is more convenient and data showed consistently better compliance with intermittent bolus. Therefore, the choice of dosing should be made upon the criteria of optimal adherence to long-term supplementation. To achieve better compliance, high doses of vitamin $\mathrm{D}_{3}$, either injected intramuscularly or administered orally once a year, have been studied. These dosing regimens display the advantages of preventing the decline of $25 \mathrm{OHD}$ normally observed during winter and being a practical intervention in a clinical setting. However, 500000 IU of vitamin $\mathrm{D}_{3}$ given to a community-dwelling of older women once a year for 3 to 5 years resulted in $15 \%$ more falls and $26 \%$ more fractures in the vitamin D group than in the placebo group. ${ }^{183}$ The increased likelihood of falls, and to a lesser extent fractures, was exacerbated in the 3-month period following the annual dose. Similarly, Smith et al. ${ }^{184}$ reported an increased risk for non-vertebral fractures in older women, but not in men, following the annual intramuscular injection of $300000 \mathrm{IU}$ of vitamin $\mathrm{D}_{2}$ for three years. The incidence of falls was, however, not influenced by treatment in this study. On the basis of the current knowledge, there is no evidence that justifies the use of annual high doses of vitamin D and it has been recently suggested to restrict intermittent higher doses of vitamin $\mathrm{D}$ to intervals not greater than $2-4$ months. ${ }^{185}$

\section{Vitamin D toxicity}

The current IOM recommendation for upper level of vitamin D is 4 $000 \mathrm{IU}$ per day $(100 \mu \mathrm{g}$ per day) for healthy individuals older than 9 years, although the IOM has stated that up to 10 000IU per day was safe. The use of very high doses of vitamin D concerns clinicians because of a fear of hypervitaminosis $\mathrm{D}$, which may result in hypercalcemia and hypercalciuria. In a recent review of randomized trials of various regimens of vitamin D supplementation, with doses ranging from $600 \mathrm{IU}$ to $10000 \mathrm{IU}$ per day, there were few reported cases of hypercalcemia and hypercalciuria, and their incidence did not differ from that observed in the placebo group. ${ }^{185}$ There is now evidence from RCTs that supplemental vitamin D may have toxicities other than simply hypercalcemia/hypercalciuria. Indeed, vitamin D exhibits a U-shape or reverse J-shape curve for risk. The risk for rickets and osteomalacia declines with increasing vitamin $\mathrm{D}$ intake or 25OHD levels. However, as these levels continue to increase, adverse effects are more likely to occur, such as the increased risk for falls and fractures with high doses of vitamin D given intermittently. ${ }^{183,184}$ Less convincingly, 25OHD levels greater than $100 \mathrm{nmoll}^{-1}$ have also been associated with a doubling of the risk for pancreatic cancer. ${ }^{186,187}$

Apart from risks of toxicity, there are potential contraindications to vitamin D supplementation in SCI individuals, and these include hypercalciuria, hypercalcemia and hyperphosphatemia. Because vitamin D promotes intestinal absorption of calcium, the intake of large amounts of vitamin D may lead to hypercalcemia. In the general population, hypercalcemia results when levels of $25 \mathrm{OHD}$ are constantly exceeding 350-500 nmol $1^{-1} .{ }^{188}$ Soon after injury and as a result of the rapid bone resorption, acute SCI people exhibit calcium levels that are in the high-normal range or are elevated in spite of vitamin D deficiency. ${ }^{189}$ These high levels of serum calcium lead to a marked increased renal excretion of calcium. Nevertheless, given that PTH is suppressed and intestinal absorption of calcium is minimal in acute SCI, introducing vitamin D/or calcium supplementation at this stage will not exacerbate hypercalciuria. No adverse effect was reported in chronic SCI studies ${ }^{15,16}$ upon the use of 2000 UI of vitamin D and $1300 \mathrm{mg}$ of elementary calcium (3 $250 \mathrm{mg}$ as calcium carbonate). However, careful assessment and monitoring are required as some drugs, concomitantly used by SCI individuals, can potentiate hypercalcemia and hypercalciuria. For example, the combination of vitamin $\mathrm{D}$ and calcium supplements and thiazide diuretics can induce hypercalcemia in this population using intermittent catheterization to manage the urinary output. ${ }^{22}$

\section{Vitamin D-statin interaction}

A few medications are classically known to affect vitamin D metabolism. However, possible interactions between statins and vitamin $\mathrm{D}$ have been recently uncovered. Statins are a proven class 
of lipid-lowering drugs that reduce the risk for CVD. However, statin compliance is problematic given the occurrence of myalgia, the most frequently reported adverse effect. Vitamin D deficiency displays similar myalgic symptoms, suggesting a possible interaction between statins and vitamin D. Normalization of $25 \mathrm{OHD}$ levels in vitamin D-insufficient patients has resulted in the resolution of statin-induced myalgia. ${ }^{190}$ Earlier findings suggested that there might be an interaction between 25OHD levels and statin effectiveness as well. Indeed, vitamin D-deficient patients $\left(<30 \mathrm{nmoll}^{-1}\right)$ who had experienced acute myocardial infarctions did not respond to low or high doses of atorvastatin in terms of TG, LDL and total cholesterol at 12 months compared with patients with insufficient $\left(30-50 \mathrm{nmoll}^{-1}\right.$ ) or normal $\left(>50 \mathrm{nmoll}^{-1}\right)$ vitamin D status. ${ }^{191}$ The authors concluded that $25 \mathrm{OHD}$ levels above $30 \mathrm{nmoll}^{-1}$ are required for atorvastatin to reduce lipid levels. Furthermore, the only study reporting the effects of supplemental vitamin D in a small sample of atorvastatin-treated patients has shown that the combination of vitamin D and atorvastatin for 6 weeks resulted in a clinically relevant decrease in serum concentration of LDL despite lower levels of atorvastatin and its active metabolites. ${ }^{192}$ These findings suggest that vitamin $\mathrm{D}$ may enhance the effect of atorvastatin therapy, and one mechanism has been postulated to account for this interaction. ${ }^{193}$ Vitamin D is a known inducer of intestinal and liver CYP3A4, the cytochrome involved in first-pass metabolism of atorvastatin, which generates active metabolites responsible for its pharmacological activity. Enhanced CYP3A4 metabolism of atorvastatin should therefore result in fast drug metabolism, an increase in the lipid-lowering effect and reduced bioavailability for muscle toxicity.

\section{Inflammation}

It can be misleading to reliably assess vitamin $\mathrm{D}$ status based on a single 25OHD measurement given that certain factors, such as systemic inflammation, may negatively impact circulating 25OHD. Indeed, it was shown that circulating 25OHD experienced a marked (that is, 40\%), rapid (that is, within $6-12 \mathrm{~h}$ post-op) and lasting (that is, up to 3 months) decline in osteoarthritic patients who underwent primary knee arthroplasty. ${ }^{194,195}$ Interestingly, this decrease was accompanied by a significant elevation of CRP levels in the first five postoperative days, which returned to normal by three months. One potential explanation for such a large decrease in 25OHD concentration is the increased urinary loss of DBP and its bound $25 \mathrm{OHD}$ as a result of the actin release from injured cells that binds to DBP and accelerates its clearance. Alternatively, 25OHD turnover may be enhanced as a consequence of its active uptake by inflammatory cells, particularly macrophages. ${ }^{194,195}$ Therefore, low levels of 25OHD could be a marker of the severity of the inflammatory process rather than a true reflection of the vitamin D status. Soon after injury, SCI individuals display acute inflammation as a result of trauma, which later becomes chronic. Although the impact of chronic inflammation on vitamin D status has never been reported, interpretation of $25 \mathrm{OHD}$ levels in a SCI context should take into consideration the patient's inflammatory status.

\section{Heterotopic ossification}

Heterotopic ossification $(\mathrm{HO})$ is a pathological process characterized by the formation of bone in extra-skeletal soft tissues. It is a relatively common complication in the acute phase of SCI where the incidence ranges from 10 to $50 \%{ }^{196,197} \mathrm{HO}$ generally occurs secondarily to trauma whereby the injured tissues release factors that stimulate the commitment of local and circulating progenitor cells into osteoblasts, an event that precedes ectopic bone formation and deposition.
In addition to the release of osteoinducive factors, other mechanisms contribute to the establishment of a permissive local microenvironment that promotes HO. These contributing factors include autonomic dysregulation, inflammatory responses, tissue hypoxia, and endocrine perturbations leading to electrolyte imbalances. ${ }^{196,198}$ Oleson et al. ${ }^{199}$ reported 12 cases of HO among a cohort of 96 patients with acute or chronic complete SCI. Interestingly, 9 out of these 12 patients had hyperparathyroidism and serum 25OHD levels below $50 \mathrm{nmoll}^{-1}$, which led the authors to conclude that $\mathrm{HO}$ appeared to correlate with elevated $\mathrm{PTH}$, but neither directly with $25 \mathrm{OHD}$ or calcium levels, which, in the latter case, remained within the reference range. Vitamin $\mathrm{D}_{3}$ supplementation (1000 IU twice daily) given with or without etidronate for 1 year resulted in the normalization of PTH values in all subjects but one, with no additional $\mathrm{HO}$ progression. The authors postulated that keeping serum $25 \mathrm{OHD}$ levels above $80 \mathrm{nmol}^{-1}$ would allow a better control of the permissive environment that underlies the development of HO. The same group documented the case of a 31-year-old patient with $\mathrm{HO}$ and nearly deficient vitamin D status (that is, $25.5 \mathrm{nmoll}^{-1}$ ) who was prescribed a weekly supplement of 50000 UI vitamin $D_{2}$ with etidronate $\left(20 \mathrm{mg} \mathrm{kg}^{-1}\right){ }^{200}$ Twelve weeks later, $25 \mathrm{OHD}$ levels had increased to $73.3 \mathrm{nmoll}^{-1}$, and flexion range of motion and rotation had improved with no worsening of $\mathrm{HO}$ at imaging.

\section{RECOMMENDATIONS FOR SCI INDIVIDUALS}

At present, there are no specific recommendations for SCI individuals. In light of the evidence reviewed here and based on the guidelines released by the Endocrine Society as well as our clinical experience, we formulated tentative recommendations that may improve current practice and inform future research endeavors. Although we formulated these recommendations following an extensive review of the literature, the selection criteria for the studies included in this review remain subjective and are not based on a systematic review of the evidence, which may lead to interpretation bias. Therefore, these recommendations should not be considered definitive, but are intended to give clinicians tools for better management of vitamin D status of SCI individuals and to serve as a starting point for systematic model analyses.

\section{Screening of vitamin D status and clinical thresholds}

We recommend that SCI individuals be considered as candidates for routine vitamin $\mathrm{D}$ screening and that their vitamin $\mathrm{D}$ status be assessed shortly after admission to a rehabilitation center, although evidence is currently insufficient to propose an ideal time frame post injury. Endocrine Society cutoffs should be used for defining 25OHD deficiency $\left(<25 \mathrm{nmoll}^{-1}\right)$ and insufficiency $\left(25-75 \mathrm{nmoll}^{-1}\right)$, although the cutoff for sufficiency remains to be defined. Even though no safe upper level of $25 \mathrm{OHD}$ has been defined in this population, caution is warranted, as potential detrimental effects have been associated with high levels of 25OHD.

\section{Assessment of vitamin D and PTH status}

Serum 25OHD remains the most reliable marker of vitamin D status, whereas measurement of $1,25(\mathrm{OH})_{2} \mathrm{D}$ levels should be considered in case of persistent hypercalciuria, hypercalcemia and/or nephrolithiasis. Circulating PTH should be checked if hypercalcemia persists.

\section{Assessment of calcium and phosphorus status}

Before initiation of vitamin D supplementation, total calcium as well as phosphorus should be assessed. If albumin and total calcium levels are within the normal range, assessment of ionized calcium is not 
indicated. Serum calcium levels should be closely monitored once vitamin D supplementation has begun.

\section{Vitamin D and calcium supplementation}

Daily or weekly regimen of vitamin D should be preferred. In the absence of strong evidence, it is premature to recommend specific doses of vitamin D for SCI individuals. Our recommendations are therefore based on those suggested by the Endocrine Society. A dose of $50000 \mathrm{IU} \mathrm{wk}^{-1}$ or $6000 \mathrm{IU} \mathrm{d}^{-1}$ for 8 weeks is suggested to correct vitamin $\mathrm{D}$ deficiency and raise $25 \mathrm{OHD}$ levels above $75 \mathrm{nmol}^{-1}$. Once achieved, a maintenance therapy of $1500-2 \quad 000 \mathrm{IU} \mathrm{d}^{-1}$ is recommended. Adjustments may be required to achieve and/or maintain circulating $25 \mathrm{OHD}$ above $75 \mathrm{nmol}^{-1}$. The clinicians must be aware of factors that may impact the $25 \mathrm{OHD}$ response to oral vitamin $\mathrm{D}$ and monitor $25 \mathrm{OHD}$ levels on a regular basis to determine the efficiency of the supplementation and adjust the dosage accordingly. For instance, individuals with growing skeletons (for example, children and adolescents) and young men deserve particular attention as hypercalcemia and hypercalciuria are more commonly seen in these subgroups of individuals. ${ }^{201,202}$

Vitamin D supplementation could be postponed in case of high inflammation markers and normal-high serum calcium. Given that osteoporosis is highly prevalent in the SCI individuals and because vitamin $\mathrm{D}$ alone is less effective than in combination with calcium, correction of vitamin D insufficiency in the presence of adequate calcium intakes is recommended, as stated by the Endocrine Society. Assessment of dietary calcium intakes should be made prior to the initiation of calcium supplementation. When intakes are high $(>1500 \mathrm{mg})$, calcium supplementation may be unnecessary or supplement dose adjusted accordingly. If calcium supplementation is required, calcium citrate remains the preferred calcium formulation as it is absorbed irrespective of the presence of stomach food and acid content. If not available, then calcium carbonate should be taken with foods. Calcium absorption is quite efficient in doses $\leqslant 500 \mathrm{mg}$; therefore, doses should be split throughout the day rather than being ingested at once.

\section{CONCLUSION}

Although high rates of vitamin D deficiency and insufficiency are encountered in SCI individuals, its consequences are not well defined. As weight-bearing activity is limited in SCI, emphasis should be made on the monitoring of nutritional factors that impact musculoskeletal and metabolic health. Routine screening and monitoring of vitamin D as well as treatment of suboptimal status should be instituted in both the acute and the chronic setting. The close interactions between vitamin $\mathrm{D}$ and related bone minerals should be kept in mind when supplementing SCI individuals, and practices should be individualized with clinical conditions.

In conclusion, we believe important knowledge gaps need to be addressed in future research dealing with vitamin D and SCI. The amount of vitamin $\mathrm{D}$ required to achieve and maintain a steady and adequate level of $25 \mathrm{OHD}$ in these individuals is unknown. As they often display disorders of mineral metabolism and risk for $\mathrm{HO}$, the safety of vitamin D should be carefully evaluated. Whether keeping 25OHD levels above a certain threshold would translate into long-lasting skeletal and extra-skeletal benefits warrants further investigation, with musculoskeletal and metabolic health as well as functional outcomes considered high priorities. Finally, the musculoskeletal impact on the combination of vitamin D and calcium with mechanical therapy should be investigated in these patients.

\section{DATA ARCHIVING}

There were no data to deposit.

\section{CONFLICT OF INTEREST}

The authors declare no conflict of interest.

\section{ACKNOWLEDGEMENTS}

JL and GM are respectively supported by a master's scholarship and a research scholar from FRQ-S (Fonds de Recherche du Québec en Santé).

1 Christakos S, Hewison M, Gardner DG, Wagner CL, Sergeev IN, Rutten E et al. Vitamin D: beyond bone. Ann NY Acad Sci 2013; 1287: 45-58.

2 Lazo MG, Shirazi P, Sam M, Giobbie-Hurder A, Blaconiere MJ, Muppidi M. Osteoporosis and risk of fracture in men with spinal cord injury. Spinal Cord 2001; 39: 208.

3 Cashman KD, Kinsella M, McNulty BA, Walton J, Gibney MJ, Flynn A et al. Dietary vitamin D2-a potentially underestimated contributor to vitamin D nutritional status of adults? Br J Nutr 2014; 112: 193-202.

4 McDonnell SL, French CB, Heaney RP. Quantifying the food sources of basal vitamin D input. J Steroid Biochem Mol Biol 2014; 144: 149-151.

5 Shakur YA, Lou W, L'Abbe MR. Examining the effects of increased vitamin D fortification on dietary inadequacy in Canada. Can J Public Health 2014; 105: e127-e132.

6 Bikle Daniel D. Vitamin D metabolism, mechanism of action, and clinical applications. Chem Biol 2014; 21: 319-329.

7 Zhou XJ, Vaziri ND, Segal JL, Winer RL, Eltorai I, Brunnemann SR. Effects of chronic spinal cord injury and pressure ulcer on $25(\mathrm{OH})$-vitamin D levels. J Am Paraplegia Soc 1993; 16: 9-13.

8 Javidan AN, Sabour H, Latifi S, Vafa M, Shidfar F, Khazaeipour Z et al. Calcium and vitamin $\mathrm{D}$ plasma concentration and nutritional intake status in patients with chronic spinal cord injury: a referral center report. J Res Med Sci 2014; 19: 881-884.

9 Bauman WA, Zhong YG, Schwartz E. Vitamin D deficiency in veterans with chronic spinal cord injury. Metabolism 1995; 44: 1612-1616.

10 Oleson CV, Patel PH, Wuermser L-A. Influence of season, ethnicity, and chronicity on vitamin D deficiency in traumatic spinal cord injury. J Spinal Cord Med 2010; 33: 202-213.

11 Nemunaitis GA, Mejia M, Nagy JA, Johnson T, Chae J, Roach MJ. A descriptive study on vitamin $D$ levels in individuals with spinal cord injury in an acute inpatient rehabilitation setting. Pm R 2010; 2: 202-208, quiz 28

12 Hummel K, Craven BC, Giangregorio L. Serum 25(OH)D, PTH and correlates of suboptimal $25(\mathrm{OH}) \mathrm{D}$ levels in persons with chronic spinal cord injury. Spinal Cord 2012; 50: 812-816.

13 Gaspar AP, Brandao CM, Lazaretti-Castro M. Bone mass and hormone analysis in patients with spinal cord injury: evidence for a gonadal axis disruption. J Clin Endocrinol Metab 2014; 99: 4649-4655

14 Vaziri ND, Pandian MR, Segal JL, Winer RL, Eltorai I, Brunnemann S. Vitamin D, parathormone, and calcitonin profiles in persons with long-standing spinal cord injury. Arch Phys Med Rehabil 1994; 75: 766-769.

15 Bauman WA, Morrison NG, Spungen AM. Viatmin D replacement therapy in persons with spinal cord injury. J Spinal Cord Med 2005; 28: 203-207.

16 Bauman WA, Emmons RR, Cirnigliaro CM, Kirshblum SC, Spungen AM. An effective oral vitamin D replacement therapy in persons with spinal cord injury. J Spinal Cord Med 2011; 34: 455-460.

17 Bauman WA, Zhang R-L, Morrison N, Spungen AM. Acute supression of bone turnover with calcium infusion in persons with spinal cord injury. J Spinal Cord Med 2009; 32: 398-403.

18 Matsuoka LY, Ide L, Wortsman J, MacLaughlin JA, Holick MF Sunscreens suppress cutaneous vitamin D3 synthesis. J Clin Endocrinol Metab 1987; 64: 1165-1168.

19 Smith EM, Comiskey CM, Carroll AM. A study of bone mineral density in adults with disability. Arch Phys Med Rehabil 2009; 90: 1127-1135.

20 Walters JL, Buchholz AC, Martin Ginis KA. Evidence of dietary inadequacy in adults with chronic spinal cord injury. Spinal Cord 2009; 47: 318-322.

21 Tomey KM, Chen DM, Wang X, Braunschweig CL. Dietary intake and nutritional status of urban community-dwelling men with paraplegia. Arch Phys Med Rehabil 2005; 86: 664-671.

22 Robien K, Oppeneer SJ, Kelly JA, Hamilton-Reeves JM. Drug-vitamin D interactions: a systematic review of the literature. Nutr Clin Pract 2013; 28: 194-208.

23 Hahn TJ, Hendin BA, Scharp CR, Haddad JG Jr. Effect of chronic anticonvulsant therapy on serum 25-hydroxycalciferol levels in adults. N Engl J Med 1972; 287: 900-904.

24 Richens A, Rowe DJF. Disturbance of calcium metabolism by anticonvulsant drugs. Br Med J 1970; 4: 73-76

25 Wang Z, Lin YS, Zheng XE, Senn T, Hashizume T, Scian M et al. An inducible cytochrome P450 3A4-dependent vitamin D catabolic pathway. Mol Pharmacol 2012; 81: 498-509.

26 Brodie MJ, Boobis AR, Dollery CT, Hillyard CJ, Brown DJ, Maclntyre I et al. Rifampicin and vitamin D metabolism. Clin Pharmacol Ther 1980; 27: 810-814. 
27 Brodie MJ, Boobis AR, Hillyard CJ, Abeyasekera G, Stevenson JC, MacIntyre I et al. Effect of rifampicin and isoniazid on vitamin D metabolism. Clin Pharmacol Ther 1982; 32: 525-530.

28 Meier C, Kraenzlin ME. Antiepileptics and bone health. Therapeut Adv Musculoskel Dis 2011; 3: 235-243.

29 Rouleau P, Guertin PA. Traumatic and nontraumatic spinal-cord-injured patients in Quebec, Canada. Part 3: pharmacological characteristics. Spinal Cord 2011; 49: $186-195$.

30 Steuer I, Rouleau P, Guertin PA. Pharmacological approaches to chronic spinal cord injury. Curr Pharm Des 2013; 19: 4423-4436.

31 Heinemann AW, Doll MD, Armstrong KJ, Schnoll S, Yarkony GM. Substance use and receipt of treatment by persons with long-term spinal cord injuries. Arch Phys Med Rehabil 1991; 72: 482-487.

32 Heinemann AW, Keen M, Donohue R, Schnoll S. Alcohol use by persons with recent spinal cord injury. Arch Phys Med Rehabil 1988; 69: 619-624.

33 Bjorneboe GE, Johnsoen J, Bjorneboe A, Rousseau B, Pedersen JI, Norum KR et al. Effect of alcohol consumption on serum concetration of 25-hydroxyvitamin D3, retinol, and retinol-binding protein. Am J Clin Nutr 1986; 44: 678-682.

34 Gascon-Barré M. Influence of chronic ethanol consumption on the metabolism and action of vitamin D. J Am Coll Nutr 1985; 4: 565-574.

35 Dusso AS, Slatopolsky E. Vitamin D and Renal Disease. In: Feldman D, Pike JW \& Adams JS (eds) Academic Press, San Diego, 2011, 1325-1357.

36 Al-Badr W, Martin KJ. Vitamin D and kidney disease. Clin J Am Soc Nephrol 2008; 3: 1555-1560.

37 Melamed ML, Astor B, Michos ED, Hostetter TH, Powe NR, Muntner P. 25-hydroxyvitamin D levels, race, and the progression of kidney disease. J Am Soc Nephrol 2009; 20: 2631-2639.

38 Fischer MJ, Krishnamoorthi VR, Smith BM, Evans CT St, Andre JR, Ganesh S et al. Prevalence of chronic kidney disease in patients with spinal cord injuries/disorders. Am J Nephrol 2012; 36: 542-548.

39 Wortsman J, Matsuoka LY, Chen TC, Lu Z, Holick MF. Decreased bioavailability of vitamin D in obesity. Am J Clin Nutr 2000; 72: 690-693.

40 Gallagher JC, Sai A, Templin T 2nd, Smith L. Dose response to vitamin D supplementation in postmenopausal women: a randomized trial. Ann Intern Med 2012; 156: 425-437.

41 Weil E, Wachterman M, McCarthy EP, Davis RB, O'Day B, lezzoni LI et al. Obesity among adults with disabling conditions. JAMA 2002; 288: 1265-1268.

42 Gupta N, White KT, Sandford PR. Body mass index in spinal cord injury-a retrospective study. Spinal Cord 2006; 44: 92-94.

43 Weaver FM, Collins EG, Kurichi J, Miskevics S, Smith B, Rajan S et al. Prevalence of obesity and high blood pressure in veterans with spinal cord injuries and disorders: a retrospective review. Am J Phys Med Rehabil 2007; 86: 22-29.

44 Jones LM, Legge M, Goulding A. Healthy body mass index values often underestimate body fat in men with spinal cord injury1. Arch Phys Med Rehabil 2003; 84: 1068-1071.

45 Mechanick JI, Pomerantz F, Flanagan S, Stein A, Gordon WA, Ragnarsson KT. Parathyroid hormone supression in spinal cord injury patients is associated with the degreee of neurologic impairment and not level of injury. Arch Phys Med Rehabil 1997; 78: 692-696.

46 Roberts D, Lee W, Cuneo RC, Wittmann J, Ward G, Flatman R et al. Longitudinal study of bone turnover after acute spinal cord injury. J Clin Endocrinol Metab 1998; 83: 415-422.

47 Bauman WA, Zhong Y-G, Schwartz E. Vitamin D deficiency in veterans with chronic spinal cord injury. Metabolism 1995; 44: 1612-1616.

48 Maimoun L, Couret I, Micallef JP, Peruchon E, Mariano-Goulart D, Rossi M et al. Use of bone biochemical markers with dual-energy $x$-ray absorptiometry for early determination of bone loss in persons with spinal cord injury. Metabolism 2002; 51: 958-963.

49 Zehnder Y, Luthi M, Michel D, Knecht H, Perrelet R, Neto I et al. Long-term changes in bone metabolism, bone mineral density, quantitative ultrasound parameters, and fracture incidence after spinal cord injury: a cross-sectional observational study in 100 paraplegic men. Osteoporos Int 2004; 15: 180-189.

50 Priemel M, von Domarus C, Klatte TO, Kessler S, Schlie J, Meier S et al. Bone mineralization defects and vitamin $D$ deficiency: histomorphometric analysis of iliac crest bone biopsies and circulating 25-hydroxyvitamin D in 675 patients. J Bone Miner Res 2010; 25: 305-312.

51 Busse B, Bale HA, Zimmermann EA, Panganiban B, Barth HD, Carriero A et al. Vitamin $D$ deficiency induces early signs of aging in human bone, increasing the risk of fracture. Sci Transl Med 2013; 10: 193ra88.

52 Dauty M, Perrouin Verbe B, Maugars Y, Dubois C, Mathe JF. Supralesional and sublesional bone mineral density in spinal cord-injured patients. Bone 2000; 27: 305-309.

53 Vestergaard P, Krogh K, Rejnmark L, Mosekilde L. Fracture rates and risk factors for fractures in patients with spinal cord injury. Spinal Cord 1998; 36: 790-796.

54 Morse LR, Battaglino RA, Stolzmann KL, Hallet LD, Waddimba A, Gagnon D et al. Osteoporotic fractures and hospitalization risk in chronic spinal cord injury. Osteoporos Int 2009; 20: 385-392.

55 Bauman WA, Cardozo CP. Osteoporosis in individuals with spinal cord injury. $\mathrm{Pm} R$ 2015; 7: 188-201.

56 Reid IR, Bolland MJ, Grey A. Effects of vitamin D supplements on bone mineral density: a systematic review and meta-analysis. Lancet 2014; 383: 146-155.
57 Bischoff-Ferrari HA, Willett WC, Wong JB, Stuck AE, Staehelin HB, Orav EJ et al. Prevention of nonvertebral fractures with oral vitamin $D$ and dose dependency: a meta-analysis of randomized controlled trials. Arch Intern Med 2009; 169: 551-561.

58 Bischoff-Ferrari HA. Relevance of vitamin D in muscle health. Rev Endocr Metab Disord 2012; 13: 71-77.

59 Avenell A, Mak JC, O'Connell D. Vitamin D and vitamin D analogues for preventing fractures in post-menopausal women and older men. Cochrane Database Syst Rev 2014; 4: Cd000227.

60 Doetsch AM, Faber J, Lynnerup N, Watjen I, Bliddal H, Danneskiold-Samsoe B. The effect of calcium and vitamin D3 supplementation on the healing of the proximal humerus fracture: a randomized placebo-controlled study. Calcif Tissue Int 2004; 75: $183-188$.

61 Kolb JP, Schilling AF, Bischoff J, Novo de Oliveira A, Spiro A, Hoffmann M et al. Calcium homeostasis influences radiological fracture healing in postmenopausal women. Arch Orthop Trauma Surg 2013; 133: 187-192.

62 Bauman WA, Spungen AM, Morrison N, Zhang RL, Schwartz E. Effect of a vitamin D analog on leg bone mineral density in patients with chronic spinal cord injury. J Rehabil Res Dev 2005; 42: 625-634.

63 Chen B, Mechanick JI, Nierman DM, Stein A. Combined calcitriol-pamidronate therapy for bone hyperresorption in spinal cord injury. J Spinal Cord Med 2001; 24: 235-240.

64 Schott GD, Wills MR. Muscle weakness in osteomalacia. Lancet 1976; 1: 626-629.

65 Girgis CM, Clifton-Bligh RJ, Turner N, Lau SL, Gunton JE. Effects of vitamin D in skeletal muscle: falls, strength, athletic performance and insulin sensitivity. Clin Endocrinol (Oxf) 2014; 80: 169-181.

66 Girgis CM, Clifton-Bligh RJ, Mokbel N, Cheng K, Gunton JE. Vitamin D signaling regulates proliferation, differentiation, and myotube size in $\mathrm{C} 2 \mathrm{C} 12$ skeletal muscle cells. Endocrinology 2014; 155: 347-357.

67 Girgis CM, Mokbel N, Cha KM, Houweling PJ, Abboud M, Fraser DR et al. The vitamin $D$ receptor (VDR) is expressed in skeletal muscle of male mice and modulates 25-hydroxyvitamin D (250HD) uptake in myofibers. Endocrinology 2014; 155: 3227-3237.

68 Bischoff HA, Borchers M, Gudat F, Duermueller U, Theiler R, Stahelin HB et al. In situ detection of 1,25-dihydroxyvitamin D3 receptor in human skeletal muscle tissue. Histochem J 2001; 33: 19-24.

69 Ceglia L, da Silva Morais M, Park LK, Morris E, Harris SS, Bischoff-Ferrari HA et al. Multi-step immunofluorescent analysis of vitamin $D$ receptor loci and myosin heavy chain isoforms in human skeletal muscle. J Mol Histol 2010; 41: 137-142.

70 Wang Y, DeLuca HF. Is the vitamin d receptor found in muscle? Endocrinology 2011; 152: 354-363.

71 Malloy PJ, Feldman D. Genetic disorders and defects in vitamin d action. Endocrinol Metab Clin North Am 2010; 39: 333-346.

72 Delvin EE, Glorieux FH, Marie PJ, Pettifor JM. Vitamin D dependency: replacement therapy with calcitriol? J Pediatr 1981; 99: 26-34.

73 Wagatsuma A, Sakuma K. Vitamin D signaling in myogenesis: potential for treatment of sarcopenia. Biomed Res Int 2014; 2014: 121254.

74 Endo I, Inoue D, Mitsui T, Umaki Y, Akaike M, Yoshizawa T et al. Deletion of vitamin D receptor gene in mice results in abnormal skeletal muscle development with deregulated expression of myoregulatory transcription factors. Endocrinology 2003; 144: 5138-5144.

75 Burne TH, McGrath JJ, Eyles DW, Mackay-Sim A. Behavioural characterization of vitamin D receptor knockout mice. Behav Brain Res 2005; 157: 299-308.

76 Srikuea R, Zhang X, Park-Sarge OK, Esser KA. VDR and CYP27B1 are expressed in C2C12 cells and regenerating skeletal muscle: potential role in suppression of myoblast proliferation. Am J Physiol Cell Physiol 2012; 303: C396-C405.

77 Girgis CM, Clifton-Bligh RJ, Hamrick MW, Holick MF, Gunton JE. The roles of vitamin $D$ in skeletal muscle: form, function, and metabolism. Endocr Rev 2013. 34: 33-83.

78 Beaudart C, Buckinx F, Rabenda V, Gillain S, Cavalier E, Slomian J et al. The effects of vitamin D on skeletal muscle strength, muscle mass, and muscle power: a systematic review and meta-analysis of randomized controlled trials. J Clin Endocrinol Metab 2014; 99: 4336-4345.

79 Redzic M, Lewis RM, Thomas DT. Relationship between 25-hydoxyvitamin D, muscle strength, and incidence of injury in healthy adults: a systematic review. Nutr rRes (New York, NY) 2013; 33: 251-258.

80 Halfon M, Phan O, Teta D. Vitamin D: a review on its effects on muscle strength, the risk of fall, and frailty. Biomed Res Int/ 2015; 2015: 11.

81 Hirani V, Cumming RG, Naganathan V, Blyth F, Le Couteur DG, Handelsman DJ et al. Associations between serum 25-hydroxyvitamin D concentrations and multiple health conditions, physical performance measures, disability, and all-cause mortality: the Concord Health and Ageing in Men Project. J Am Geriatr Soc 2014; 62: 417-425.

82 Spedding S, Vanlint S, Morris H, Scragg R. Does vitamin D sufficiency equate to a single serum 25-hydroxyvitamin $\mathrm{D}$ level or are different levels required for non-skeletal diseases? Nutrients 2013; 5: 5127-5139.

83 Stockton KA, Mengersen K, Paratz JD, Kandiah D, Bennell KL. Effect of vitamin D supplementation on muscle strength: a systematic review and meta-analysis. Osteoporos Int 2011; 22: 859-871.

84 Qin W, Bauman WA, Cardozo C. Bone and muscle loss after spinal cord injury: organ interactions. Ann NY Acad Sci 2010; 1211: 66-84

85 Biering-Sorensen B, Kristensen IB, Kjaer M, Biering-Sorensen F. Muscle after spinal cord injury. Muscle a d Nerve 2009; 40: 499-519.

86 Ceglia L, Niramitmahapanya S, da Silva Morais M, Rivas DA, Harris SS, Bischoff-Ferrari $\mathrm{H}$ et al. A randomized study on the effect of vitamin $D(3)$ 
supplementation on skeletal muscle morphology and vitamin $\mathrm{D}$ receptor concentration in older women. J Clin Endocrinol Metab 2013; 98: E1927-E1935.

87 Feron F, Marqueste T, Bianco J, Gueye Y, Chabas JF, Decherchi P. Repairing the spinal cord with vitamin D: a promising strategy. Biol Aujourdhui 2014; 208: 69-75.

88 Gueye $\mathrm{Y}$, Marqueste $\mathrm{T}$, Maurel F, Khrestchatisky M, Decherchi P, Feron F. Cholecalciferol (vitamin D) improves functional recovery when delivered during the acute phase after a spinal cord trauma. J Steroid Biochem Mol Biol 2015; 154 23-31.

89 Barbonetti A, Sperandio A, Micillo A, D'Andrea S, Pacca F, Felzani G et al. Independent Association of Vitamin D With Physical Function in People With Chronic Spinal Cord Injury. Arch Phys Med Rehabil 2016; 97: 726-732.

90 Aminmansour B, Asnaashari A, Rezvani M, Ghaffarpasand F. Amin Noorian SM, Saboori $\mathrm{M}$ et al. Effects of progesterone and vitamin $\mathrm{D}$ on outcome of patients with acute traumatic spinal cord injury; a randomized, double-blind, placebo controlled study. J Spinal Cord Med 2016; 39: 272-280.

91 Li YC. Chapter 40: Vitamin D and the Renin-Angiotensin System. In: Feldman D, Pike JW \& Adams JS (eds). Vitamin D, 3rd ed., Academic Press, San Diego, 2011, pp 707-723.

92 Dong J, Wong SL, Lau CW, Lee HK, Ng CF, Zhang L et al. Calcitrio protects renovascular function in hypertension by down-regulating angiotensin II type 1 receptors and reducing oxidative stress. Eur Heart J 2012; 33: 2980-2990.

93 Li YC, Kong J, Wei M, Chen ZF, Liu SQ, Cao LP. 1,25-Dihydroxyvitamin D(3) is a negative endocrine regulator of the renin-angiotensin system. J Clin Invest 2002; 110 229-238.

94 Pilz S, Tomaschitz A, Ritz E, Pieber TR. Vitamin D status and arterial hypertension: a systematic review. Nat Rev Cardiol 2009; 6: 621-630.

95 Kienreich K, Grubler M, Tomaschitz A, Schmid J, Verheyen N, Rutters F et al. Vitamin D, arterial hypertension \& cerebrovascular disease. Indian J Med Res 2013; 137: 669-679.

96 Beveridge LA, Struthers AD, Khan F, Jorde R, Scragg R, Macdonald HM et al. Effect of Vitamin D Supplementation on Blood Pressure: A Systematic Review and Meta-analysis Incorporating Individual Patient Data. JAMA Intern Medne 2015; 175 745-754.

97 Kunutsor S, Burgess S, Munroe P, Khan H. Vitamin D and high blood pressure: causal association or epiphenomenon? Eur J Epidemiol 2014; 29: 1-14.

98 Witham MD, Ireland S, Houston JG, Gandy SJ, Waugh S, Macdonald TM et al. Vitamin D therapy to reduce blood pressure and left ventricular hypertrophy in resistant hypertension: randomized, controlled trial. Hypertension 2014; 63: 706-712.

99 Arora P, Song Y, Dusek J, Plotnikoff G, Sabatine MS, Cheng S et al. Vitamin D therapy in individuals with prehypertension or hypertension: the DAYLIGHT trial. Circulation 2015; 131: 254-262.

100 Phillips AA, Krassioukov AV. Contemporary cardiovascular concerns after spinal cord injury: mechanisms, maladaptations, and management. J Neurotrauma 2015; 32 1927-1942.

101 Libin A, Tinsley EA, Nash MS, Mendez AJ, Burns P, Elrod M et al. Cardiometabolic risk clustering in spinal cord injury: results of exploratory factor analysis. Top Spinal Cord Injury Rehabil 2013; 19: 183-194.

102 Wong KE, Szeto FL, Zhang W, Ye H, Kong J, Zhang Z et al. Involvement of the vitamin $\mathrm{D}$ receptor in energy metabolism: regulation of uncoupling proteins. Am J Physio 2009. 296: E820-E828.

103 Reid IR. Effects of calcium supplementation on circulating lipids: potential pharmacoeconomic implications. Drugs Aging 2004; 21: 7-17.

104 McCarty DE, Chesson AL Jr, Jain SK, Marino AA. The link between vitamin D metabolism and sleep medicine. Sleep Med Rev 2014; 18: 311-319.

105 Taniguchi A, Kataoka K, Kono T, Oseko F, Okuda H, Nagata I et al. Parathyroid hormone-induced lipolysis in human adipose tissue. J Lipid Res 1987; 28: 490-494.

106 Jorde R, Grimnes G. Vitamin D and metabolic health with special reference to the effect of vitamin D on serum lipids. Prog Lipid Res 2011; 50: 303-312.

107 Maki KC, Rubin MR, Wong LG, McManus JF, Jensen CD, Marshall JW et al. Serum 25-hydroxyvitamin $D$ is independently associated with high-density lipoprotein cholesterol and the metabolic syndrome in men and women. J Clin Lipidol 2009; 3 289-296.

108 Wang H, Xia N, Yang Y, Peng DQ. Influence of vitamin D supplementation on plasma lipid profiles: a meta-analysis of randomized controlled trials. Lipids Health Dis 2012, 11: 42

109 Elamin MB, Abu Elnour NO, Elamin KB, Fatourechi MM, Alkatib AA, Almandoz JP et al. Vitamin $\mathrm{D}$ and cardiovascular outcomes: a systematic review and meta-analysis. $J$ Clin Endocrinol Metab 2011; 96: 1931-1942.

110 Bellan M, Guzzaloni G, Rinaldi M, Merlotti E, Ferrari C, Tagliaferri A et al. Altered glucose metabolism rather than naive type 2 diabetes mellitus (T2DM) is related to vitamin D status in severe obesity. Cardiovasc Diabetol 2014; 13: 57.

111 Gilbert O, Croffoot JR, Taylor AJ, Nash M, Schomer K, Groah S. Serum lipid concentrations among persons with spinal cord injury-a systematic review and metaanalysis of the literature. Atherosclerosis 2014; 232: 305-312.

112 Rouleau P, Guertin PA. Traumatic and non-traumatic spinal cord-injured patients in Quebec, Canada. Part 2: biochemical profile. Spinal Cord 2010; 48: 819-824.

113 Lewington S, Whitlock G, Clarke R, Sherliker P, Emberson J, Halsey J et al. Blood cholesterol and vascular mortality by age, sex, and blood pressure: a meta-analysis of individual data from 61 prospective studies with 55,000 vascular deaths. Lancet 2007: 370: 1829-1839.

114 Wang TJ, Pencina MJ, Booth SL, Jacques PF, Ingelsson E, Lanier K et al. Vitamin D deficiency and risk of cardiovascular disease, Circulation 2008: 117: 503-511.
115 Kim DH, Sabour S, Sagar UN, Adams S, Whellan DJ. Prevalence of hypovitaminosis D in cardiovascular diseases (from the National Health and Nutrition Examination Survey 2001 to 2004). Am J Cardiol 2008: 102: 1540-1544.

116 Laclaustra M, Van Den Berg EL, Hurtado-Roca Y, Castellote JM. Serum lipid profile in subjects with traumatic spinal cord injury. PLOS ONE 2015; 10 e0115522.

117 Norman AW, Frankel JB, Heldt AM, Grodsky GM. Vitamin D deficiency inhibits pancreatic secretion of insulin. Science 1980; 209: 823-825.

118 Beaulieu C, Kestekian R, Havrankova J, Gascon-Barre M. Calcium is essential in normalizing intolerance to glucose that accompanies vitamin $\mathrm{D}$ depletion in vivo. Diabetes 1993; 42: 35-43.

119 Bland R, Markovic D, Hills CE, Hughes SV, Chan SL, Squires PE et al. Expression of 25-hydroxyvitamin D3-1alpha-hydroxylase in pancreatic islets. J Steroid Biochem Mol Biol 2004; 89-90: 121-125

120 Zeitz U, Weber K, Soegiarto DW, Wolf E, Balling R, Erben RG. Impaired insulin secretory capacity in mice lacking a functional vitamin D receptor. FASEB J 2003; 17 509-511.

121 Lee S, Clark SA, Gill RK, Christakos S. 1,25-Dihydroxyvitamin D3 and pancreatic beta-cell function: vitamin $D$ receptors, gene expression, and insulin secretion. Endocrinology 1994; 134: 1602-1610.

122 Maestro B, Campion J, Davila N, Calle C. Stimulation by 1,25-dihydroxyvitamin D3 of insulin receptor expression and insulin responsiveness for glucose transport in U-937 human promonocytic cells. Endocr J 2000; 47: 383-391.

123 Zhou QG, Hou FF, Guo ZJ, Liang M, Wang GB, Zhang X. 1,25-Dihydroxyvitamin D improved the free fatty-acid-induced insulin resistance in cultured $\mathrm{C} 2 \mathrm{C} 12$ cells. Diabetes Metab Res Rev 2008; 24: 459-464.

124 Scragg R, Sowers M, Bell C. Serum 25-hydroxyvitamin D, diabetes, and ethnicity in the Third National Health and Nutrition Examination Survey. Diabetes Care 2004; 27: 2813-2818.

125 Hypponen E, Boucher BJ, Berry DJ, Power C. 25-hydroxyvitamin D, IGF-1, and metabolic syndrome at 45 years of age: a cross-sectional study in the 1958 British Birth Cohort. Diabetes 2008; 57: 298-305.

126 Lu L, Yu Z, Pan A, Hu FB, Franco OH, Li H et al. Plasma 25-hydroxyvitamin D concentration and metabolic syndrome among middle-aged and elderly Chinese individuals. Diabetes Care 2009: 32: 1278-1283.

127 Hirani V, Cumming RG, Le Couteur DG, Naganathan V, Blyth F, Handelsman DJ et al. Low levels of 25-hydroxy vitamin D and active 1,25-dihydroxyvitamin D independently associated with type 2 diabetes mellitus in older Australian men: the Concord Health and Ageing in Men Project. J Am Geriatr Soc 2014; 62: 1741-1747.

128 Song Y, Wang L, Pittas AG, Del Gobbo LC, Zhang C, Manson JE et al. Blood 25-hydroxy vitamin $D$ levels and incident type 2 diabetes: a meta-analysis of prospective studies. Diabetes Care 2013; 36: 1422-1428.

129 Afzal S, Bojesen SE, Nordestgaard BG. Low 25-hydroxyvitamin D and risk of type 2 diabetes: a prospective cohort study and metaanalysis. Clin Chem 2013; 59 381-391.

130 Khan H, Kunutsor S, Franco OH, Chowdhury R. Vitamin D, type 2 diabetes and other metabolic outcomes: a systematic review and meta-analysis of prospective studies. Proc Nutr Soc 2013; 72: 89-97.

131 Tsur A, Feldman BS, Feldhammer I, Hoshen MB, Leibowitz G, Balicer RD. Decreased serum concentrations of 25-hydroxycholecalciferol are associated with increased risk of progression to impaired fasting glucose and diabetes. Diabetes Care 2013; 36 : $1361-1367$.

132 Pittas AG, Harris SS, Stark PC, Dawson-Hughes B. The effects of calcium and vitamin D supplementation on blood glucose and markers of inflammation in nondiabetic adults. Diabetes Care 2007; 30: 980-986.

133 Mitri J, Dawson-Hughes B, Hu FB, Pittas AG. Effects of vitamin D and calcium supplementation on pancreatic beta cell function, insulin sensitivity, and glycemia in adults at high risk of diabetes: the Calcium and Vitamin D for Diabetes Mellitus (CaDDM) randomized controlled trial. Am J Clin Nutr 2011; 94: 486-494.

134 Dutta D, Mondal SA, Choudhuri S, Maisnam I, Hasanoor Reza AH, Bhattacharya B et al. Vitamin-D supplementation in prediabetes reduced progression to type 2 diabetes and was associated with decreased insulin resistance and systemic inflammation: an open label randomized prospective study from Eastern India. Diabetes Res Clin Pract 2014; 103: e18-e23.

135 Strobel F, Reusch J, Penna-Martinez M, Ramos-Lopez E, Klahold E, Klepzig C. Effect of a randomised controlled vitamin $D$ trial on insulin resistance and glucose metabolism in patients with type 2 diabetes mellitus. Horm Metab Res 2014; 46 : $54-58$

136 Tabesh M, Azadbakht L, Faghihimani E, Tabesh M, Esmaillzadeh A. Effects of calcium-vitamin D co-supplementation on metabolic profiles in vitamin D insufficient people with type 2 diabetes: a randomised controlled clinical trial. Diabetologia 2014; 57: 2038-2047.

137 Davidson MB, Duran P, Lee ML, Friedman TC. High-dose vitamin D supplementation in people with prediabetes and hypovitaminosis D. Diabetes Care 2013; 36: 260-266.

138 Oosterwerff MM, Eekhoff EM, Van Schoor NM, Boeke AJ, Nanayakkara P, Meijnen $\mathrm{R}$ et al. Effect of moderate-dose vitamin $\mathrm{D}$ supplementation on insulin sensitivity in vitamin D-deficient non-Western immigrants in the Netherlands: a randomized placebo-controlled trial. Am J Clin Nutr 2014; 100: 152-160. 
139 Pilz S, Rutters F, Dekker JM. Comment on: Davidson et al. high-dose vitamin D supplementation in people with prediabetes and hypovitaminosis D. Diabetes Care 2013; 36: 260-266. Diabetes Care. 2013; 36: e71.

140 Maudar V, Lafavor J, Hollis B, Gobejishvili L, Olive J, Barve S et al. Alterations in glucose tolerance and vascular function in subjects with chronic spinal cord injury: Association with adipokines and systemic inflammation. 70th Scientific Sessions of the American Diabetes Association, Orlando, FL, 2010.

141 Elder CP, Apple DF, Bickel CS, Meyer RA, Dudley GA. Intramuscular fat and glucose tolerance after spinal cord injury - a cross-sectional study. Spinal Cord 2004; 42: 711-716.

142 Vimaleswaran KS, Berry DJ, Lu C, Tikkanen E, Pilz S, Hiraki LT et al. Causal relationship between obesity and vitamin D status: bi-directional Mendelian randomization analysis of multiple cohorts. PLoS Med 2013; 10: e1001383.

143 Blumberg JM, Tzameli I, Astapova I, Lam FS, Flier JS, Hollenberg AN. Complex role of the vitamin D receptor and its ligand in adipogenesis in 3T3-L1 cells. J Biol Chem 2006; 281: 11205-11213.

144 Nimitphong H, Holick MF, Fried SK, Lee MJ. 25-hydroxyvitamin D(3) and 1,25-dihydroxyvitamin $\mathrm{D}(3)$ promote the differentiation of human subcutaneous preadipocytes. PLOS ONE 2012; 7: e52171.

145 Zemel MB, Shi H, Greer B, Dirienzo D, Zemel PC. Regulation of adiposity by dietary calcium. FASEB J 2000; 14: 1132-1138.

146 Mora N, Rieke K, Plitcha J, Segura A, Leehey D, DeShong K et al. 25-Hydroxyvitamin $\mathrm{D}$ supplementation and BMI change: a meta-analysis of randomized controlled trials. J Obesity Weightloss Ther 2013; 3: 181.

147 Chandler PD, Wang L, Zhang X, Sesso HD, Moorthy MV, Obi $O$ et al. Effect of vitamin $\mathrm{D}$ supplementation alone or with calcium on adiposity measures: a systematic review and meta-analysis of randomized controlled trials. Nutr Rev 2015; 73: 577-593.

148 Wang L, Song Y, Manson JE, Pilz S, Marz W, Michaelsson K et al. Circulating 25-hydroxy-vitamin $D$ and risk of cardiovascular disease: a meta-analysis of prospective studies. Circ Cardiovasc Qual Outcomes 2012; 5: 819-829.

149 Perna L, Schottker B, Holleczek B, Brenner H. Serum 25-hydroxyvitamin D and incidence of fatal and nonfatal cardiovascular events: a prospective study with repeated measurements. J Clin Endocrinol Metab 2013; 98: 4908-4915.

150 Camargo CA Jr. Vitamin D and cardiovascular disease: time for large randomized trials. J Am Coll Cardiol 2011; 58: 1442-1444.

151 Hsia J, Heiss G, Ren H, Allison M, Dolan NC, Greenland P et al. Calcium/vitamin D supplementation and cardiovascular events. Circulation 2007; 115: 846-854.

152 Wang L, Manson JE, Song Y, Sesso HD. Systematic review: vitamin D and calcium supplementation in prevention of cardiovascular events. Ann Intern Med 2010; 152: 315-323.

153 Ford JA, MacLennan GS, Avenell A, Bolland M, Grey A, Witham M et al. Cardiovascular disease and vitamin $D$ supplementation: trial analysis, systematic review, and meta-analysis. Am J Clin Nutr 2014; 100: 746-755.

154 Myers J, Lee M, Kiratli J. Cardiovascular disease in spinal cord injury: an overview of prevalence, risk, evaluation, and management. Am J Phys Med Rehabil 2007; 86: 142-152.

155 Cragg JJ, Noonan VK, Krassioukov A, Borisoff J. Cardiovascular disease and spinal cord injury: results from a national population health survey. Neurology 2013; 81: 723-728.

156 Kressler J, Cowan RE, Bigford GE, Nash MS. Reducing cardiometabolic disease in spinal cord injury. Phys Med Rehabil Clin N Am 2014; 25: 573-604, viii.

157 Parker J, Hashmi O, Dutton D, Mavrodaris A, Stranges S, Kandala NB et al. Levels of vitamin $\mathrm{D}$ and cardiometabolic disorders: systematic review and meta-analysis. Maturitas 2010; 65: 225-236.

158 Ju SY, Jeong HS, Kim do H. Blood vitamin D status and metabolic syndrome in the general adult population: a dose-response meta-analysis. J Clin Endocrinol Metab 2014; 99: 1053-1063.

159 Alberti K, Eckel R, Grundy S, Zimmet P, Cleeman L, Donato K et al. Harmonizing the metabolic syndrome: a join interim statement of the International Diabetes Federation Task Force on Epidemiology and Prevention; National Heart, Lung and Blood Institute; American Heart Association; World Heart Federation; International Atherosclerosis Society; and International Association for the Study of Obesity. Circulation 2009; 120 1640-1645.

160 Kaur J. A comprehensive review on metabolic syndrome. Cardiol Res Pract 2014; 2014: 943162

161 Carlsson AC, Wandell PE, Halldin M, de Faire U, Hellenius ML. Is a unified definition of metabolic syndrome needed? Comparison of three definitions of metabolic syndrome in 60-year-old men and women. Metab 2009; 7: 231-241.

162 Jones LM, Legge M, Goulding A. Factor analysis of the metabolic syndrome in spinal cord-injured men. Metabolism 2004; 53: 1372-1377.

163 Liang H, Chen D, Wang Y, Rimmer JH, Braunschweig CL. Different risk factor patterns for metabolic syndrome in men with spinal cord injury compared with able-bodied men despite similar prevalence rates. Arch Phys Med Rehabil 2007; 88: 1198-1204.

164 Nash MS, Cowan RE, Kressler J. Evidence-based and heuristic approaches for customization of care in cardiometabolic syndrome after spinal cord injury. J Spinal Cord Med 2012; 35: 278-292.

165 Lee MY, Myers J, Hayes A, Madan S, Froelicher VF, Perkash I et al. C-reactive protein, metabolic syndrome, and insulin resistance in individuals with spinal cord injury. J Spinal Cord Med 2005; 28: 20-25.
166 Maruyama Y, Mizuguchi M, Yaginuma T, Kusaka M, Yoshida H, Yokoyama K et al. Serum leptin, abdominal obesity and the metabolic syndrome in individuals with chronic spinal cord injury. Spinal Cord 2008; 46: 494-499.

167 Ravensbergen HJC, Lear SA, Claydon VE. Waist circumference is the best index for obesity-related cardiovascular disease risk in individuals with spinal cord injury. J Neurotrauma 2013; 31: 292-300.

168 Schladen MM, Groah SL. State of the science on cardiometabolic risk after spinal cord injury: Recap of the 2013 ASIA pre-conference on cardiometabolic disease. Top Spinal Cord Injury Rehabil 2014; 20: 105-112.

169 Szlachcic Y, Stewart CA, Ayyoub Z, Adkins RH. Metabolic correlates of 5-year longitudinal changes in fat distribution in persons with chronic SCl. J Spinal Cord Med 2009; 32: 455-456.

170 Mazahery $\mathrm{H}$, von Hurst PR. Factors affecting 25-hydroxyvitamin D concentration in response to vitamin D supplementation. Nutrients 2015; 7: 5111-5142.

171 Rizzoli R, Boonen S, Brandi ML, Bruyere O, Cooper C, Kanis JA et al. Vitamin D supplementation in elderly or postmenopausal women: a 2013 update of the 2008 recommendations from the European Society for Clinical and Economic Aspects of Osteoporosis and Osteoarthritis (ESCEO). Curr Med Res Opin 2013; 29: 305-313.

172 Rosen CJ, Abrams SA, Aloia JF, Brannon PM, Clinton SK, Durazo-Arvizu RA et al. IOM committee members respond to Endocrine Society vitamin D guideline. J Clin Endocrinol Metab 2012; 97: 1146-1152.

173 Theodoratou E, Tzoulaki I, Zgaga J, Ioannidis JPA . Vitamin D and multiple health outcomes: umbrella review of systematic reviews and meta-analyses of observational studies and randomised trials. BMJ 2014; 348: g2035.

174 Ahn J, Yu K, Stolzenberg-Solomon R, Simon KC, McCullough ML, Gallicchio L et al. Genome-wide association study of circulating vitamin D levels. Hum Mol Genet 2010; 19: 2739-2745.

175 Fu L, Yun F, Oczak M, Wong BY, Vieth R, Cole DE. Common genetic variants of the vitamin $\mathrm{D}$ binding protein (DBP) predict differences in response of serum 25-hydroxyvitamin D [25(OH)D] to vitamin D supplementation. Clin Biochem 2009; 42: 1174-1177.

176 Nissen J, Vogel U, Ravn-Haren G, Andersen EW, Madsen KH, Nexo BA et al Common variants in CYP2R1 and GC genes are both determinants of serum 25-hydroxyvitamin $D$ concentrations after UVB irradiation and after consumption of vitamin D(3)-fortified bread and milk during winter in Denmark. Am J Clin Nutr 2015; 101: 218-227.

177 Heaney RP, Recker RR, Grote J, Horst RL, Armas LA. Vitamin D(3) is more potent than vitamin D(2) in humans. J Clin Endocrinol Metab 2011; 96: E447-E452

178 Holick MF, Biancuzzo RM, Chen TC, Klein EK, Young A, Bibuld D et al. Vitamin D2 is as effective as vitamin D3 in maintaining circulating concentrations of 25-hydroxyvitamin D. J Clin Endocrinol Metab 2008; 93: 677-681.

179 Lanham-New S, Vieth R, Heaney R. Vitamin D2 and vitamin D3 comparisons: fundamentally flawed study methodology. Am J Clin Nutr 2010; 92: 999.

180 Tripkovic L, Lambert H, Hart K, Smith CP, Bucca G, Penson S et al. Comparison of vitamin $D_{2}</$ and vitamin $D_{3}<$ sub $>3</$ sub $>$ supplementation in raising serum 25-hydroxyvitamin D status: a systematic review and meta-analysis. Am J Clin Nutr 2012; 95: 1357-1364.

181 Ish-Shalom S, Segal E, Salganik T, Raz B, Bromberg IL, Vieth R. Comparison of daily, weekly, and monthly vitamin D3 in ethanol dosing protocols for two months in elderly hip fracture patients. J Clin Endocrinol Metab 2008; 93: 3430-3435.

182 Binkley N, Gemar D, Engelke J, Gangnon R, Ramamurthy R, Krueger D et al. Evaluation of ergocalciferol or cholecalciferol dosing, $1600 \mathrm{IU}$ daily or $50000 \mathrm{IU}$ monthly in older adults. J Clin Endocrinol Metab 2011; 96: 981-988.

183 Sanders KM, Stuart AL, Williamson EJ, Simpson JA, Kotowicz MA, Young D et al. Annual high-dose oral vitamin $D$ and falls and fractures in older women: a randomized controlled trial. JAMA 2010; 303: 1815-1822.

184 Smith H, Anderson F, Raphael H, Maslin P, Crozier S, Cooper C. Effect of annual intramuscular vitamin $\mathrm{D}$ on fracture risk in elderly men and women-a populationbased, randomized, double-blind, placebo-controlled trial. Rheumatology (Oxford) 2007; 46: 1852-1857.

185 Sanders KM, Nicholson GC, Ebeling PR. Is high dose vitamin D harmful? Calcif Tissue Int 2013; 92: 191-206.

186 Baggerly LL, Garland CF. Vitamin D and pancreatic cancer risk - no U-shaped curve. Anticancer Res 2012; 32: 981-984.

187 Stolzenberg-Solomon RZ, Jacobs EJ, Arslan AA, Qi D, Patel AV, Helzlsouer KJ et al. Circulating 25-hydroxyvitamin D and risk of pancreatic cancer: Cohort Consortium Vitamin D Pooling Project of Rarer Cancers. Am J Epidemiol 2010; 172: 81-93.

188 Jones G. Pharmacokinetics of vitamin D toxicity. Am J Clin Nutr 2008; 88: 582 S-586.

189 Stewart AF, Adler M, Byers CM, Segre GV, Broadus AE. Calcium homeostasis in immobilization: an example of resorptive hypercalciuria. N Engl J Med 1982; 306: $1136-1140$.

190 Lee P, Greenfield JR, Campbell LV. Vitamin D insufficiency-a novel mechanism of statin-induced myalgia? Clin Endocrinol (Oxf) 2009; 71: 154-155.

191 Pérez-Castrillón JL, Abad Manteca L, Vega G, del Pino Montes J, de Luis D, Dueňas Laita A. Vitamin D levels and lipid response to atorvastatin. Int J Endocrinol 2010; 2010: 4.

192 Schwartz JB. Effects of vitamin D supplementation in atorvastatin-treated patients: a new drug interaction with an unexpected consequence. Clin Pharmacol Ther 2009; 85: 198-203.

193 Bhattacharyya S, Bhattacharyya K, Maitra A. Possible mechanisms of interaction between statins and vitamin. QJM 2012; 105: 487-491. 
194 Waldron JL, Ashby HL, Cornes MP, Bechervaise J, Razavi C, Thomas OL et al. Vitamin D: a negative acute phase reactant. J Clin Pathol 2013; 66: 620-622.

195 Reid D, Toole BJ, Knox S, Talwar D, Harten J, O'Reilly DS et al. The relation between acute changes in the systemic inflammatory response and plasma 25-hydroxyvitamin D concentrations after elective knee arthroplasty. Am J Clin Nutr 2011; 93: 1006-1011.

196 Sakellariou VI, Grigoriou E, Mavrogenis AF, Soucacos PN, Papagelopoulos PJ. Heterotopic ossification following traumatic brain injury and spinal cord injury: insight into the etiology and pathophysiology. J Musculoskelet Neuronal Interact 2012; 12: 230-240.

197 Citak M, Suero EM, Backhaus M, Aach M, Godry H, Meindl R et al. Risk factors for heterotopic ossification in patients with spinal cord injury. Spine J 2012; 37: 1953-1957.
198 van Kuijk AA, Geurts AC, van Kuppevelt HJ. Neurogenic heterotopic ossification in spinal cord injury. Spinal Cord 2002; 40: 313-326.

199 Oleson CV, Seidel BJ, Zhan T. Association of vitamin D deficiency, secondary hyperparathyroidism, and heterotopic ossification in spinal cord injury. J Rehabil Res Dev 2013; 50: 1177-1186.

200 Seidel BJ, Oleson CV. Management of vitamin D deficiency in the presence of active heterotopic ossification. Poster presented at the 40th Anniversary ASIA Annual Meeting 2013, Chicago, IL, USA.

201 Maynard FM. Immobilization hypercalcemia following spinal cord injury. Arch Phys Med Rehabil 1986; 67: 41-44.

202 Merli GJ, McElwain GE, Adler AG, Martin JH, Roberts JD, Schnall B et al. Immobilization hypercalcemia in acute spinal cord injury treated with etidronate. Arch Intern Med 1984; 144: 1286-1288. 